\title{
Design of Coibamide A Mimetics with Improved Cellular Bioactivity
}

\author{
Takashi Kitamura, ${ }^{\dagger}$ Rikito Suzuki, ${ }^{\dagger}{ }^{\S}$ Shinsuke Inuki, ${ }^{\dagger}$ Hiroaki Ohno, ${ }^{\dagger}$ \\ Kerry L. McPhail, ${ }^{\ddagger}$ and Shinya Oishi*,†,§
}

${ }^{\dagger}$ Graduate School of Pharmaceutical Sciences, Kyoto University, Sakyo-ku, Kyoto 606-8501, Japan Department of Pharmaceutical Sciences, College of Pharmacy, Oregon State University, Corvallis, Oregon 97331, United States

§Department of Medicinal Chemistry, Kyoto Pharmaceutical University, Yamashina-ku, Kyoto 607-8412, Japan

E-mail: soishi@mb.kyoto-phu.ac.jp

\section{Table of Contents}

Experimental section $\quad$ S2

$\begin{array}{ll}\text { Structures of reported Sec61 inhibitors } & \text { S13 }\end{array}$

$\begin{array}{ll}\text { Synthesis of [Bph10]-coibamide A } & \text { S14 }\end{array}$

$\begin{array}{ll}\text { References } & \text { S15 }\end{array}$

$\begin{array}{ll}\text { NMR spectra } & \text { S16 }\end{array}$ 


\section{Experimental section}

\section{Synthetic general method}

${ }^{1} \mathrm{H}$ and ${ }^{13} \mathrm{C}$ NMR spectra were recorded using a JEOL ECA-500 spectrometer. Chemical shifts are reported in $\delta(\mathrm{ppm})$, relative to $\mathrm{Me}_{4} \mathrm{Si}$ (in $\mathrm{CDCl}_{3}$ ) as an internal standard for ${ }^{1} \mathrm{H}$, and referenced to the residual solvent signal for ${ }^{13} \mathrm{C}$. Exact mass (HRMS) data were recorded on a Shimadzu LC-ESI-ITTOF-MS equipment. Optical rotations were measured using a JASCO P-1020 polarimeter. For flash chromatography, Wakogel C-300E (Wako) was employed. For analytical HPLC, a Cosmosil 5C18ARII column $\left(4.6 \times 250 \mathrm{~mm}\right.$, Nacalai Tesque, Inc.) was employed with a linear gradient of $\mathrm{CH}_{3} \mathrm{CN}$ (with $0.1 \%(\mathrm{v} / \mathrm{v}) \mathrm{TFA}$ ) in $\mathrm{H}_{2} \mathrm{O}$, and eluting products were detected by $\mathrm{UV}$ at $220 \mathrm{~nm}$. Preparative HPLC was performed using a Cosmosil 5C18-ARII preparative column $(20 \times 250 \mathrm{~mm}$, Nacalai Tesque, Inc.). The compound purity for the bioassays was determined to be $>90 \%$ by HPLC analysis.

Fmoc-MeSer(Me)-OH. Fmoc-MeSer(Me)-OH was synthesized by the identical procedure reported previously. ${ }^{\mathrm{S} 1, \mathrm{~S} 2}$ To a suspension of Fmoc-Ser(Me)-OH $(5.74 \mathrm{~g}, 16.8 \mathrm{mmol})$ in toluene $(300 \mathrm{~mL})$, paraformaldehyde $(3.33 \mathrm{~g}, 111 \mathrm{mmol})$ and $\mathrm{TsOH} \cdot \mathrm{H}_{2} \mathrm{O}(320 \mathrm{mg}, 1.68 \mathrm{mmol})$ were added, and the mixture was refluxed for $2 \mathrm{~h}$. The solution was washed with aqueous $\mathrm{NaHCO}_{3}$ and brine, and dried over $\mathrm{MgSO}_{4}$. After concentration, the crystalline product was dissolved in $\mathrm{CHCl}_{3} / \mathrm{TFA}(1: 1,170 \mathrm{~mL})$, and $\mathrm{Et}_{3} \mathrm{SiH}(8.04 \mathrm{~mL}, 50.4 \mathrm{mmol})$ was added. The solution was stirred at room temperature for $22 \mathrm{~h}$ followed by concentration to give an oily residue. Purification by flash chromatography on silica gel ( $\mathrm{CHCl}_{3}: \mathrm{MeOH}=1: 0$ to 20:1) provided Fmoc-MeSer(Me)-OH as a colorless oil (5.87 g, 98\% for 2 steps). The spectral data were in good agreement with those previously reported. ${ }^{\mathrm{S} 2}$

Alloc-Bph-OH. To a suspension of H-Bph-OH (419 mg, $1.74 \mathrm{mmol})$ in THF $(0.91 \mathrm{~mL})$ and $\mathrm{H}_{2} \mathrm{O}$ $(1.93 \mathrm{~mL})$, allyl chloroformate $(185 \mu \mathrm{L}, 1.74 \mathrm{mmol})$ and $2.0 \mathrm{M}$ aqueous $\mathrm{NaOH}(1.74 \mathrm{~mL})$ were added at room temperature. After being stirred for $3.5 \mathrm{~h}$, the reaction mixture was concentrated. The residue was acidified with $2.0 \mathrm{M} \mathrm{HCl}$, and extracted with EtOAc. The extract was washed with brine, and dried over $\mathrm{MgSO}_{4}$. After concentration, the residue was recrystallized from $n$-hexane-EtOAc to provide Alloc-Bph-OH as a white solid (489 mg, 86\%): $[\alpha]^{25} \mathrm{D}+76.2\left(c 0.52, \mathrm{CHCl}_{3}\right) ;{ }^{1} \mathrm{H}$ NMR (500 $\left.\mathrm{MHz}_{2} \mathrm{CDCl}_{3}\right) \delta: 3.12-3.28(\mathrm{~m}, 2 \mathrm{H}), 4.57$ (d, $\left.J=5.5 \mathrm{~Hz}, 2 \mathrm{H}\right), 4.69-4.76(\mathrm{~m}, 1 \mathrm{H}), 5.14-5.24(\mathrm{~m}, 2 \mathrm{H})$, $5.28(\mathrm{~d}, J=17.0 \mathrm{~Hz}, 1 \mathrm{H}) 5.87-5.93(\mathrm{~m}, 1 \mathrm{H}), 7.25(\mathrm{~d}, J=7.5 \mathrm{~Hz}, 2 \mathrm{H}), 7.33(\mathrm{t}, J=7.5 \mathrm{~Hz}, 1 \mathrm{H}), 7.42$ $(\mathrm{t}, J=7.5 \mathrm{~Hz}, 2 \mathrm{H}), 7.48-7.62(\mathrm{~m}, 4 \mathrm{H}) ;{ }^{13} \mathrm{C} \mathrm{NMR}\left(125 \mathrm{MHz}, \mathrm{CDCl}_{3}\right) \delta: 37.3,54.5,66.0,118.0,127.0$, $127.3,127.4,128.8,129.7,132.4,134.5,140.1,140.6,155.8,176.1$; HRMS (ESI-TOF) calcd for $\mathrm{C}_{19} \mathrm{H}_{20} \mathrm{NO}_{4}[\mathrm{M}+\mathrm{H}]^{+}:$326.1387; found: 326.1388 . 
Preparation of N-terminal ester moiety.

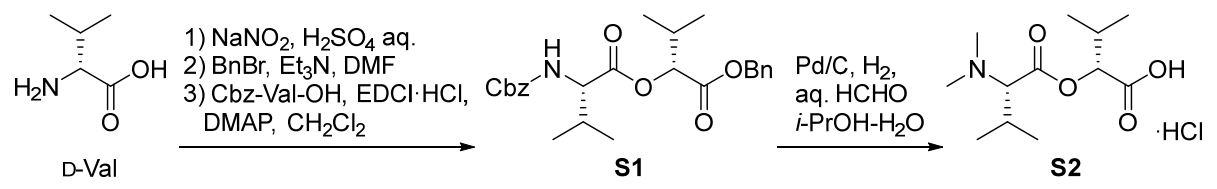

Cbz-Val-D-Hva-OBn (S1). To a solution of D-valine $(27.9 \mathrm{~g}, 238 \mathrm{mmol})$ in $0.5 \mathrm{M} \mathrm{H}_{2} \mathrm{SO}_{4}(950 \mathrm{~mL})$, a solution of $\mathrm{NaNO}_{2}(98.2 \mathrm{~g}, 1.43 \mathrm{~mol})$ in $\mathrm{H}_{2} \mathrm{O}(325 \mathrm{~mL})$ was added dropwise at $0{ }^{\circ} \mathrm{C}$. The mixture was stirred for $10 \mathrm{~h}$ at room temperature. The whole was extracted with $\mathrm{Et}_{2} \mathrm{O}$ and the extract was washed with brine, and dried over $\mathrm{MgSO}_{4}$. The filtrate was concentrated under reduced pressure to give crude H-D-Hva-OH (25.4 g), which was used for the next step without further purification. To a stirred solution of crude H-D-Hva-OH (20.7 g, ca. $175 \mathrm{mmol})$ and Et $3 \mathrm{~N}$ (48.8 mL, $350 \mathrm{mmol})$ in dry $\operatorname{DMF}(100 \mathrm{~mL}), \mathrm{BnBr}(19.8 \mathrm{~mL}, 166 \mathrm{mmol})$ was added dropwise at $0^{\circ} \mathrm{C}$. The mixture was stirred for $18 \mathrm{~h}$ at room temperature. The resulting mixture was diluted with EtOAc and the whole was washed with citric acid aq., $\mathrm{NaHCO}_{3}$ aq., and brine, and dried over $\mathrm{MgSO}_{4}$. The filtrate was concentrated under reduced pressure to give crude H-D-Hva-OBn (18.9 g), which was used for the next step without further purification. To a mixture of H-D-Hva-OBn (18.9 g, ca. $90.6 \mathrm{mmol})$, Cbz-Val-OH $(27.3 \mathrm{~g}, 109 \mathrm{mmol})$ and DMAP $(1.11 \mathrm{~g}, 9.06 \mathrm{mmol})$ in dry $\mathrm{CH}_{2} \mathrm{Cl}_{2}(180 \mathrm{~mL})$, EDCI $\cdot \mathrm{HCl}(34.6 \mathrm{~g}, 181$ mmol) was added at $0{ }^{\circ} \mathrm{C}$. The mixture was stirred for $24 \mathrm{~h}$ at room temperature. After concentration, the residue was diluted with EtOAc. The whole was washed with citric acid aq., $\mathrm{NaHCO}_{3}$ aq., and brine, and dried over $\mathrm{MgSO}_{4}$. Purification by flash column chromatography on silica gel ( $n$ hexane:EtOAc $=5: 1)$ provided compound $\mathbf{S 1}$ as a colorless oil $(38.0 \mathrm{~g}, 44 \%$ for 3 steps $):[\alpha]^{26}{ }_{\mathrm{D}}+15.3$ (c $\left.0.79, \mathrm{CHCl}_{3}\right) ;{ }^{1} \mathrm{H}$ NMR $\left(500 \mathrm{MHz}, \mathrm{CDCl}_{3}\right) \delta$ : 0.89-1.00 (m, 12H), 2.19-2.43 (m, 2H), 4.44 (dd, $J$ $=9.5,4.0 \mathrm{~Hz}, 1 \mathrm{H}), 4.90(\mathrm{~d}, J=4.0 \mathrm{~Hz}, 1 \mathrm{H}), 5.11-5.21(\mathrm{~m}, 4 \mathrm{H}), 5.27(\mathrm{~d}, J=9.5 \mathrm{~Hz}, 1 \mathrm{H}), 7.24-7.40$ $(\mathrm{m}, 10 \mathrm{H}) ;{ }^{13} \mathrm{C} \mathrm{NMR}\left(125 \mathrm{MHz}, \mathrm{CDCl}_{3}\right) \delta: 17.0,17.2,18.7,19.0,30.0,31.1,59.1,66.9,67.0,77.4$, 128.10, 128.13, 128.3, 128.4, 128.46, 128.49, 135.1, 136.1, 156.1, 169.0, 171.4; HRMS (ESI-TOF) calcd for $\mathrm{C}_{25} \mathrm{H}_{31} \mathrm{NNaO}_{6}[\mathrm{M}+\mathrm{Na}]^{+}$: 464.2044; found: 464.2044 .

Me 2 Val-D-Hva-OH·HCI (S2). To a solution of Cbz-Val-D-Hva-OBn S1 (304 mg, $0.688 \mathrm{mmol})$ in $i$ $\operatorname{PrOH}(2.4 \mathrm{~mL})$ was added $10 \% \mathrm{Pd} / \mathrm{C}(42.4 \mathrm{mg})$ and formaldehyde $(37 \%, 513 \mu \mathrm{L}, 6.88 \mathrm{mmol})$. The mixture was stirred under $\mathrm{H}_{2}$ at room temperature for $24 \mathrm{~h}$. The resulting mixture was filtered using a membrane filter (Advantec T050A025A, $0.50 \mu \mathrm{m}$ ) and concentrated under reduced pressure. The residue was purified by a CombiFlash ${ }^{\circledR}$ Rf 150 apparatus using a C18 reversed phase column to provide TFA salt. To replace TFA counterions with chloride ions, the product was lyophilized in the presence of $\mathrm{HCl}$, which gave $\mathbf{S 2}$ as a white solid $(133 \mathrm{mg}, 68 \%):[\alpha]^{25} \mathrm{D}+8.59\left(c 0.55, \mathrm{CHCl}_{3}\right) ;{ }^{1} \mathrm{H}$ NMR (500 MHz, $\left.\mathrm{CDCl}_{3}\right) \delta: 1.00(\mathrm{~d}, J=7.0 \mathrm{~Hz}, 3 \mathrm{H}), 1.02-1.09(\mathrm{~m}, 6 \mathrm{H}), 1.31(\mathrm{~d}, J=6.5 \mathrm{~Hz}, 3 \mathrm{H})$, 2.34-2.44 (m, 2H), $3.00(\mathrm{~s}, 6 \mathrm{H}), 3.88(\mathrm{~d}, J=7.0 \mathrm{~Hz}, 1 \mathrm{H}), 5.02(\mathrm{~d}, J=3.5 \mathrm{~Hz}, 1 \mathrm{H}) ;{ }^{13} \mathrm{C}$ NMR $(125$ 
$\mathrm{MHz}, \mathrm{CDCl}_{3}$ ) $\delta: 16.7,17.8,18.9,20.0,27.5,29.2,41.6,71.9,78.8,167.0,169.8$; HRMS (ESI-TOF) calcd for $\mathrm{C}_{12} \mathrm{H}_{24} \mathrm{NO}_{4}[\mathrm{M}+\mathrm{H}]^{+}: 246.1700$; found: 246.1699 .

\section{General procedure for solid-phase peptide synthesis.}

Loading of an amino acid on the solid support. A solution of Fmoc amino acid (0.198 mmol) and DIEA $(138 \mu \mathrm{L}, 0.792 \mathrm{mmol})$ in dry $\mathrm{CH}_{2} \mathrm{Cl}_{2}(2.0 \mathrm{~mL})$, was added to (2-Cl)Trt chloride resin (204 $\mathrm{mg}$, $0.326 \mathrm{mmol})$. The reaction was continued for $2 \mathrm{~h}$ at room temperature.

Deprotection of Fmoc group. The Fmoc-protected peptidyl resin was treated with 20\% piperidine/DMF for $20 \mathrm{~min}$.

Coupling reaction using HATU/DIEA. DIEA $(104 \mu \mathrm{L}, 0.600 \mathrm{mmol})$ was added to a solution of Fmoc amino acid (0.30 mmol) and HATU (110 mg, $0.290 \mathrm{mmol})$ in DMF. The whole was poured into the peptidyl resin $(0.10 \mathrm{mmol})$, and the reaction was continued for $1.5 \mathrm{~h}$ at $40{ }^{\circ} \mathrm{C}$. For the coupling of $\mathrm{N}$ terminal ester moiety (S2), an excess amount of DIEA $(157 \mu \mathrm{L}, 0.900 \mathrm{mmol})$ was used.

Coupling reaction using DIC/HOBt. DIC ( $46 \mu \mathrm{L}, 0.30 \mathrm{mmol})$ was added to a solution of Fmoc amino acid $(0.30 \mathrm{mmol})$ and $\mathrm{HOBt} \cdot \mathrm{H}_{2} \mathrm{O}(46 \mathrm{mg}, 0.30 \mathrm{mmol})$ in DMF. The whole was poured into the peptidyl resin $(0.100 \mathrm{mmol})$, and the reaction was continued for $1.5 \mathrm{~h}$ at $40{ }^{\circ} \mathrm{C}$.

$N$-Methylation on solid support. ${ }^{\mathrm{S} 4} 2,4,6$-Collidine $(132 \mu \mathrm{L}, 1.00 \mathrm{mmol})$ was added to a solution of $\mathrm{NsCl}(111 \mathrm{mg}, 0.500 \mathrm{mmol})$ in NMP. The whole was poured into the peptidyl resin $(0.100 \mathrm{mmol})$, and the reaction was continued for $15 \mathrm{~min}$ at room temperature. After removal of the reagent solution, a solution of $\mathrm{MeOH}(20 \mu \mathrm{L}, 0.50 \mathrm{mmol})$ and $\mathrm{Ph}_{3} \mathrm{P}(131 \mathrm{mg}, 0.500 \mathrm{mmol})$ in dry THF was added into the peptidyl resin. DEAD $(228 \mu \mathrm{L}, 0.500 \mathrm{mmol})$ was added dropwise, and the reaction was continued for $30 \mathrm{~min}$ at room temperature. This reaction was repeated twice. To a suspension of the peptidyl resin in NMP, DBU $(75 \mu \mathrm{L}, 0.50 \mathrm{mmol})$ and 2-mercaptoethanol $(70 \mu \mathrm{L}, 1.0 \mathrm{mmol})$ were added, and the reaction was continued for $5 \mathrm{~min}$. This deprotection process was repeated twice.

Deprotection of Alloc group. To the peptidyl resin $(0.100 \mathrm{mmol})$ were added $\mathrm{PhSiH}_{3}(247 \mu \mathrm{L}, 2.00$ $\mathrm{mmol})$ and $\mathrm{Pd}\left(\mathrm{PPh}_{3}\right)_{4}(23 \mathrm{mg}, 0.020 \mathrm{mmol})$ in dry $\mathrm{CH}_{2} \mathrm{Cl}_{2}$, and the reaction was continued for $10 \mathrm{~min}$. Cleavage from the resin. The peptidyl resin was treated with 1,1,1,3,3,3-hexafluoropropan-2-ol (HFIP) $/ \mathrm{CH}_{2} \mathrm{Cl}_{2}$ (3:7) for $2 \mathrm{~h}$ at room temperature. After filtration of the residual resin, the filtrate was concentrated under reduced pressure to give a crude peptide, which was used for the next step without further purification.

$\left[\mathrm{MeAla}^{3}\right.$, MeLys(Me) $\left.{ }^{5}, \mathrm{MeAla}^{6}\right]$-Coibamide A (2a). The linear peptide was constructed by solidphase peptide synthesis on peptidyl resin $3(0.490 \mathrm{mmol} / \mathrm{g}, 204 \mathrm{mg}, 0.100 \mathrm{mmol})$. After the cleavage from the resin 7 as described above, $\mathrm{EDCI} \cdot \mathrm{HCl}(192 \mathrm{mg}, 1.00 \mathrm{mmol})$ was added to a solution of linear 
peptide, HOAt $(136 \mathrm{mg}, 1.00 \mathrm{mmol})$, and DIEA $(697 \mu \mathrm{L}, 4.00 \mathrm{mmol})$ in dry DMF $(100 \mathrm{~mL})$ at $0{ }^{\circ} \mathrm{C}$. The reaction mixture was allowed to warm up to room temperature and the stirring was continued for $18 \mathrm{~h}$. The reaction mixture was concentrated and the residue was purified by RP-HPLC to give $\mathbf{2 a}$ (5.9 mg, 4.4\% from resin) as a white powder: ${ }^{1} \mathrm{H} \mathrm{NMR}\left(500 \mathrm{MHz}, \mathrm{CDCl}_{3}\right.$, mixture of rotamers) $\delta$ : 0.69-1.04 (m, 27H), 1.08-1.15 (m, 4H), 1.15-1.22 (m, 4H), 1.22-1.29 (m, 4H), 1.29-1.37 (m, 4H), 1.37-1.76 (m, 9H), 1.76-1.97 (m, 2H), 2.00-2.29 (m, 3H), 2.42-2.53 (m, 1H), 2.57-2.74 (m, 3H), 2.74$3.15(\mathrm{~m}, 27 \mathrm{H}), 3.78(\mathrm{~s}, 2 \mathrm{H}), 3.79(\mathrm{~s}, 1 \mathrm{H}), 3.83-3.90(\mathrm{~m}, 1 \mathrm{H}), 4.23(\mathrm{~d}, J=11.0 \mathrm{~Hz}, 1 \mathrm{H}), 4.29-4.41(\mathrm{~m}$, $0.5 \mathrm{H}), 4.85-5.17(\mathrm{~m}, 3.5 \mathrm{H}), 5.35-5.57(\mathrm{~m}, 4 \mathrm{H}), 6.47(\mathrm{~d}, J=8.5 \mathrm{~Hz}, 0.5 \mathrm{H}), 6.74-6.87(\mathrm{~m}, 2.5 \mathrm{H}), 6.99$ $(\mathrm{d}, J=8.5 \mathrm{~Hz}, 0.5 \mathrm{H}), 7.07(\mathrm{~d}, J=8.5 \mathrm{~Hz}, 1 \mathrm{H}), 7.08-7.18(\mathrm{~m}, 0.5 \mathrm{H}), 8.02($ br s, $0.5 \mathrm{H}), 8.28(\mathrm{~d}, J=$ $10.0 \mathrm{~Hz}, 0.5 \mathrm{H}) ;{ }^{13} \mathrm{C} \mathrm{NMR}\left(125 \mathrm{MHz}, \mathrm{CDCl}_{3}\right.$, mixture of rotamers) $\delta: 9.9,11.3,14.1,14.37,14.44$, $15.3,15.5,15.6,16.3,16.4,18.0,18.3,18.69,18.74,18.8,19.0,20.0,20.8,21.2,21.3,21.57,21.62$, 22.2, 22.6, 23.0, 23.2, 24.4, 24.65, 24.74, 24.9, 25.3, 26.1, 26.4, 27.78, 27.81, 28.6, 28.7, 28.8, 28.9, 29.0, 29.3, 29.55, 29.60, 29.7, 29.9, 30.1, 32.2, 32.5, 33.0, 33.4, 35.2, 37.3, 37.4, 37.5, 37.7, 38.9, $39.4,42.1,43.9,46.3,48.3,48.6,49.7,49.8,50.2,50.5,50.8,51.1,51.3,52.3,52.9,54.9,58.4,65.2$, 70.6, 70.6, 113.4, 113.8, 127.7, 127.8, 129.9, 130.2, 158.3, 158.4, 167.3, 167.4, 167.6, 168.2, 168.6, 169.4, 170.2 170.3 170.4, 170.5, 170.9, 171.0, 171.1, 172.1, 172.4, 172.4; HRMS (ESI-TOF) calcd for $\mathrm{C}_{62} \mathrm{H}_{107} \mathrm{~N}_{10} \mathrm{O}_{12}[\mathrm{M}+\mathrm{H}]^{+}$: 1183.8064; found: 1183.8070 .

$\left[\mathrm{MeAla}^{3}, \mathrm{D}-\mathrm{MeLys}(\mathrm{Me})^{5}\right.$, MeAla $\left.{ }^{6}\right]$-Coibamide A (2b). According to the procedure described for the preparation of 2a, peptidyl resin $3(0.690 \mathrm{mmol} / \mathrm{g}, 145 \mathrm{mg}, 0.100 \mathrm{mmol})$ was converted into $\mathbf{2 b}$ (10.3 mg, 8\% from resin) as a white powder: HRMS (ESI-TOF) calcd for $\mathrm{C}_{62} \mathrm{H}_{106} \mathrm{~N}_{10} \mathrm{NaO}_{12}$ $[\mathrm{M}+\mathrm{Na}]^{+}: 1205.7884$; found: 1205.7864 .

$\left[\mathrm{MeAla}^{3}, \mathrm{MeOrn}(\mathrm{Me})^{5}, \mathrm{MeAla}^{6}\right]-C o i b a m i d e ~ A ~(2 c)$. According to the procedure described for the preparation of $2 \mathbf{a}$, peptidyl resin $3(0.690 \mathrm{mmol} / \mathrm{g}, 145 \mathrm{mg}, 0.100 \mathrm{mmol})$ was converted into $2 \mathbf{c}(27.6$ $\mathrm{mg}, 22 \%$ from resin) as a white powder: HRMS (ESI-TOF) calcd for $\mathrm{C}_{61} \mathrm{H}_{105} \mathrm{~N}_{10} \mathrm{O}_{12}[\mathrm{M}+\mathrm{H}]^{+}$: 1169.7908; found: 1169.7909 .

$\left[\mathrm{MeAla}^{3}, \mathrm{D}-\mathrm{MeOrn}(\mathrm{Me})^{5}, \mathrm{MeAla}^{6}\right]$-Coibamide A (2d). According to the procedure described for the preparation of $\mathbf{2 a}$, peptidyl resin $3(0.690 \mathrm{mmol} / \mathrm{g}, 145 \mathrm{mg}, 0.100 \mathrm{mmol})$ was converted into $\mathbf{2 d}$ (9.5 mg, 7\% from resin) as a white powder: HRMS (ESI-TOF) calcd for $\mathrm{C}_{61} \mathrm{H}_{104} \mathrm{~N}_{10} \mathrm{NaO}_{12}[\mathrm{M}+\mathrm{Na}]^{+}$: 1191.7727; found: 1191.7740 .

$\left[\mathrm{MeAla}^{3}, \mathrm{MeLys}^{5}, \mathrm{MeAla}^{6}\right]-$ Coibamide A (2e). According to the procedure described for the 
preparation of 2a, peptidyl resin $3(0.490 \mathrm{mmol} / \mathrm{g}, 204 \mathrm{mg}, 0.100 \mathrm{mmol})$ was converted into $2 \mathrm{e}(25.6$ mg, 20\% from resin) as a white powder: HRMS (ESI-TOF) calcd for $\mathrm{C}_{61} \mathrm{H}_{105} \mathrm{~N}_{10} \mathrm{O}_{12}[\mathrm{M}+\mathrm{H}]^{+}$: 1169.7908; found: 1169.7909 .

$\left[\mathrm{MeAla}^{3}, \mathrm{D}^{-M e L y s}{ }^{5}, \mathrm{MeAla}^{6}\right]$-Coibamide A (2f). According to the procedure described for the preparation of 2a, peptidyl resin $3(0.690 \mathrm{mmol} / \mathrm{g}, 145 \mathrm{mg}, 0.100 \mathrm{mmol})$ was converted into $2 \mathbf{f}$ (17.2 $\mathrm{mg}, 13 \%$ from resin) as a white powder: HRMS (ESI-TOF) calcd for $\mathrm{C}_{61} \mathrm{H}_{105} \mathrm{~N}_{10} \mathrm{O}_{12}[\mathrm{M}+\mathrm{H}]^{+}$: 1169.7908; found: 1169.7906 .

$\left[\mathbf{M e A l a}^{3}, \mathbf{M e O r n}^{5}, \mathbf{M e A l a}^{6}\right]$-Coibamide A (2g). According to the procedure described for the preparation of 2a, peptidyl resin $3(0.690 \mathrm{mmol} / \mathrm{g}, 145 \mathrm{mg}, 0.100 \mathrm{mmol})$ was converted into $\mathbf{2 g}$ (19.4 $\mathrm{mg}, 15 \%$ from resin) as a white powder: HRMS (ESI-TOF) calcd for $\mathrm{C}_{60} \mathrm{H}_{103} \mathrm{~N}_{10} \mathrm{O}_{12}[\mathrm{M}+\mathrm{H}]^{+}$: 1155.7751; found: 1155.7756 .

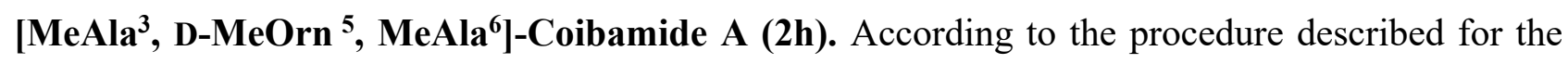
preparation of $\mathbf{2 a}$, peptidyl resin $3(0.690 \mathrm{mmol} / \mathrm{g}, 145 \mathrm{mg}, 0.100 \mathrm{mmol})$ was converted into $\mathbf{2 h}(19.8$ mg, $16 \%$ from resin) as a white powder: HRMS (ESI-TOF) calcd for $\mathrm{C}_{60} \mathrm{H}_{103} \mathrm{~N}_{10} \mathrm{O}_{12}[\mathrm{M}+\mathrm{H}]^{+}$: 1155.7751; found: 1155.7753 .

$\left[\mathrm{Ala}^{3}, \operatorname{MeLys}(\mathrm{Me})^{5}, \mathrm{MeAla}^{6}\right]-C o i b a m i d e ~ A ~(8 a)$. According to the procedure described for the preparation of 2a, peptidyl resin $3(0.690 \mathrm{mmol} / \mathrm{g}, 145 \mathrm{mg}, 0.100 \mathrm{mmol})$ was converted into $\mathbf{8 a}(6.9$ mg, 5\% from resin) as a white powder: HRMS (ESI-TOF) calcd for $\mathrm{C}_{61} \mathrm{H}_{104} \mathrm{~N}_{10} \mathrm{NaO}_{12}[\mathrm{M}+\mathrm{Na}]^{+}$: 1191.7727; found: 1191.7742 .

$\left[\mathrm{MeAla}^{3}, \mathbf{L e u}^{4}, \operatorname{MeLys}(\mathrm{Me})^{5}, \mathrm{MeAla}^{6}\right]-C o i b a m i d e$ A $(\mathbf{8 b})$. According to the procedure described for the preparation of 2a, peptidyl resin $3(0.690 \mathrm{mmol} / \mathrm{g}, 145 \mathrm{mg}, 0.100 \mathrm{mmol})$ was converted into $\mathbf{8 b}$ (5.4 mg, 4\% from resin) as a white powder: HRMS (ESI-TOF) calcd for $\mathrm{C}_{61} \mathrm{H}_{106} \mathrm{~N}_{10} \mathrm{O} 12[\mathrm{M}+2 \mathrm{H}]^{2+}$ : 585.3991; found: 585.3975 .

$\left[\mathrm{MeAla}^{3}, \mathrm{Lys}(\mathrm{Me})^{5}, \mathrm{MeAla}^{6}\right]$-Coibamide A (8c). According to the procedure described for the preparation of 2a, peptidyl resin $3(0.690 \mathrm{mmol} / \mathrm{g}, 145 \mathrm{mg}, 0.100 \mathrm{mmol})$ was converted into $8 \mathbf{c}(8.5$ $\mathrm{mg}, 7 \%$ from resin) as a white powder: HRMS (ESI-TOF) calcd for $\mathrm{C}_{61} \mathrm{H}_{105} \mathrm{~N}_{10} \mathrm{O}_{12}[\mathrm{M}+\mathrm{H}]^{+}$: 1169.7908; found: 1169.7922 . 


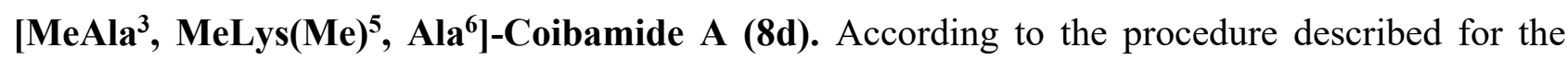
preparation of 2a, peptidyl resin $3(0.690 \mathrm{mmol} / \mathrm{g}, 145 \mathrm{mg}, 0.100 \mathrm{mmol})$ was converted into $\mathbf{8 d}(8.8$ mg, 7\% from resin) as a white powder: HRMS (ESI-TOF) calcd for $\mathrm{C}_{61} \mathrm{H}_{106} \mathrm{~N}_{10} \mathrm{O}_{12}[\mathrm{M}+2 \mathrm{H}]^{2+}$ : 585.3991; found: 585.3976 .

$\left[\mathrm{MeAla}^{3}, \operatorname{MeLys}(\mathrm{Me})^{5}, \mathrm{MeAla}^{6}\right.$, Ile $\left.^{7}\right]$-Coibamide A (8e). According to the procedure described for the preparation of $\mathbf{2 a}$, peptidyl resin $3(0.690 \mathrm{mmol} / \mathrm{g}, 145 \mathrm{mg}, 0.100 \mathrm{mmol})$ was converted into $\mathbf{8 e}$ (11.6 mg, 9\% from resin) as a white powder: HRMS (ESI-TOF) calcd for $\mathrm{C}_{61} \mathrm{H}_{106} \mathrm{~N}_{10} \mathrm{O} 12[\mathrm{M}+2 \mathrm{H}]^{2+}$ : 585.3991; found: 585.3990 .

$\left[\mathrm{MeAla}^{3}, \operatorname{MeLys}(\mathrm{Me})^{5}, \mathrm{MeAla}^{6}, \mathrm{Leu}^{9}\right]$-Coibamide A (8f). According to the procedure described for the preparation of $\mathbf{2 a}$, peptidyl resin $3(0.690 \mathrm{mmol} / \mathrm{g}, 145 \mathrm{mg}, 0.100 \mathrm{mmol})$ was converted into $\mathbf{8 f}$ (11.6 mg, 9\% from resin) as a white powder: HRMS (ESI-TOF) calcd for $\mathrm{C}_{61} \mathrm{H}_{104} \mathrm{~N}_{10} \mathrm{NaO}_{12}[\mathrm{M}+\mathrm{Na}]^{+}$: 1191.7727; found: 1191.7734 .

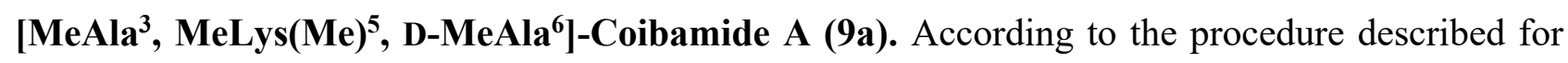
the preparation of 2a, peptidyl resin $3(0.690 \mathrm{mmol} / \mathrm{g}, 145 \mathrm{mg}, 0.100 \mathrm{mmol})$ was converted into 9a (3.5 mg, 3\% from resin) as a white powder: HRMS (ESI-TOF) calcd for $\mathrm{C}_{62} \mathrm{H}_{107} \mathrm{~N}_{10} \mathrm{O}_{12}[\mathrm{M}+\mathrm{H}]^{+}$: 1183.8064; found: 1183.8070 .

$\left[\mathrm{MeAla}^{3}, \operatorname{MeLys}(\mathrm{Me})^{5}, \mathrm{MeAla}^{6}, \mathrm{D}-\right.$ allo-MeIle $\left.^{7}\right]-$ Coibamide A (9b). According to the procedure described for the preparation of 2a, peptidyl resin $3(0.690 \mathrm{mmol} / \mathrm{g}, 145 \mathrm{mg}, 0.100 \mathrm{mmol})$ was converted into $\mathbf{9 b}(2.3 \mathrm{mg}, 2 \%$ from resin) as a white powder: HRMS (ESI-TOF) calcd for $\mathrm{C}_{62} \mathrm{H}_{107} \mathrm{~N}_{10} \mathrm{O} 12[\mathrm{M}+\mathrm{H}]^{+}:$1183.8064; found: 1183.8066 .

$\left[\mathrm{MeAla}^{3}, \operatorname{MeLys}(\mathrm{Me})^{5}, \mathrm{MeAla}^{6}, \mathrm{D}^{6} \mathrm{Ala}^{8}\right]$-Coibamide A (9c). According to the procedure described for the preparation of 2a, peptidyl resin $3(0.690 \mathrm{mmol} / \mathrm{g}, 145 \mathrm{mg}, 0.100 \mathrm{mmol})$ was converted into 9c (3.2 mg, 3\% from resin) as a white powder: HRMS (ESI-TOF) calcd for $\mathrm{C}_{62} \mathrm{H}_{106} \mathrm{~N}_{10} \mathrm{NaO}_{12}$ $[\mathrm{M}+\mathrm{Na}]^{+}: 1205.7884$; found: 1205.7830 .

$\left[\mathrm{MeAla}^{3}, \mathrm{MeLys}_{(\mathrm{Me})}{ }^{5}, \mathrm{MeAla}^{6}, \mathrm{D}-\mathrm{MeLeu}^{9}\right]$-Coibamide A (9d). According to the procedure described for the preparation of 2a, peptidyl resin $3(0.570 \mathrm{mmol} / \mathrm{g}, 175 \mathrm{mg}, 0.100 \mathrm{mmol})$ was converted into 9d (13.4 mg, 10\% from resin) as a white powder: HRMS (ESI-TOF) calcd for $\mathrm{C}_{62} \mathrm{H}_{107} \mathrm{~N}_{10} \mathrm{O}_{12}[\mathrm{M}+\mathrm{H}]^{+}:$1183.8064; found: 1183.8063 . 
$\left[\mathrm{MeAla}^{3}, \operatorname{MeLys}(\mathrm{Me})^{5}, \mathrm{MeAla}^{6}, \mathrm{D}-\mathrm{Tyr}(\mathrm{Me})^{10}\right]$-Coibamide A (9e). According to the procedure described for the preparation of 2a, peptidyl resin $3(0.490 \mathrm{mmol} / \mathrm{g}, 204 \mathrm{mg}, 0.100 \mathrm{mmol})$ was converted into $9 \mathrm{e}(4.4 \mathrm{mg}, 3 \%$ from resin) as a white powder: HRMS (ESI-TOF) calcd for $\mathrm{C}_{62} \mathrm{H}_{107} \mathrm{~N}_{10} \mathrm{O}_{12}[\mathrm{M}+\mathrm{H}]^{+}:$1183.8064; found: 1183.8059 .

$\left[\mathrm{MeAla}^{3}, \operatorname{MeLys}(\mathrm{Me})^{5}, \mathrm{MeAla}^{6}, \mathbf{B p h}^{10}\right]$-Coibamide A (10j). According to the procedure described for the preparation of 2a, peptidyl resin $3(0.490 \mathrm{mmol} / \mathrm{g}, 204 \mathrm{mg}, 0.100 \mathrm{mmol})$ was converted into $\mathbf{1 0 j}$ (16.2 mg, 12\% from resin) as a white powder: ${ }^{1} \mathrm{H} \mathrm{NMR}\left(500 \mathrm{MHz}, \mathrm{CDCl}_{3}\right.$, mixture of rotamers) $\delta: 0.66-1.79(\mathrm{~m}, 51 \mathrm{H}), 1.79-2.00(\mathrm{~m}, 2 \mathrm{H}), 2.00-2.32(\mathrm{~m}, 3 \mathrm{H}), 2.41-2.85(\mathrm{~m}, 9 \mathrm{H}), 2.85-3.31(\mathrm{~m}, 22 \mathrm{H})$, 3.78-3.95 (m, 1H), $4.21(\mathrm{~m}, 0.5 \mathrm{H}), 4.28-4.46(\mathrm{~m}, 0.5 \mathrm{H}), 4.74-5.21(\mathrm{~m}, 4 \mathrm{H}), 5.21-5.69(\mathrm{~m}, 4 \mathrm{H}), 6.52$ $(\mathrm{d}, J=8.5 \mathrm{~Hz}, 0.5 \mathrm{H}), 6.83$ (br s, 0.5H), $7.18(\mathrm{~d}, J=8.0 \mathrm{~Hz}, 1 \mathrm{H}), 7.24(\mathrm{~d}, J=8.0 \mathrm{~Hz}, 1 \mathrm{H}), 7.31-7.39$ (m, 1H), 7.39-7.48 (m, 2H), $7.52(\mathrm{~d}, J=8.0 \mathrm{~Hz}, 1 \mathrm{H}), 7.55-7.69(\mathrm{~m}, 3 \mathrm{H}), 7.97$ (br s, 0.5H), $8.52(\mathrm{~d}, J$ $=9.5 \mathrm{~Hz}, 0.5 \mathrm{H}) ;{ }^{13} \mathrm{C} \mathrm{NMR}\left(125 \mathrm{MHz}, \mathrm{CDCl}_{3}\right.$, mixture of rotamers) $\delta: 10.2,11.7,14.5,14.7,14.8$, $15.5,15.8,16.0,16.7,16.9,18.3,18.6,19.1,19.18,19.22,19.3,20.4,21.2,21.6,21.9,22.0,22.7$, 23.0, 23.3, 23.6, 24.8, 25.0, 25.1, 25.2, 25.4, 26.6, 26.9, 28.16, 28.20, 29.00, 29.04, 29.1, 29.3, 29.7, 29.91, 29.94, 30.1, 30.2, 30.3, 30.4, 32.5, 32.8, 33.5, 33.8, 35.6, 37.7, 37.8, 37.9, 38.5, 39.5, 39.9, 42.5, 44.4, 46.6, 48.8, 49.0, 50.0, 50.1, 50.4, 50.6, 51.5, 51.6, 52.6, 53.4, 58.8, 65.5, 70.8, 70.9, 126.8, 126.9, 127.0, 127.3, 127.4, 127.5, 128.8, 128.9, 129.7, 130.3, 135.1, 135.4, 139.7, 139.9, 140.1, 140.5, $167.7,167.8,167.9,168.5,169.1,169.9,170.6,170.8,170.9,171.25,171.29,171.34,172.5,172.6$, 172.7; HRMS (ESI-TOF) calcd for $\mathrm{C}_{67} \mathrm{H}_{109} \mathrm{~N}_{10} \mathrm{O}_{11}[\mathrm{M}+\mathrm{H}]^{+}$: 1229.8272; found: 1229.8254 .

$\left[\mathrm{MeAla}^{3}, \operatorname{MeLys}(\mathrm{Me})^{5}, \mathrm{MeAla}^{6}, \mathrm{Phe}^{10}\right]$-Coibamide A (10a). According to the procedure described for the preparation of $\mathbf{2 a}$, peptidyl resin $\mathbf{6}(0.100 \mathrm{mmol})$ was converted into $\mathbf{1 0 a}(4.2 \mathrm{mg}, 3 \%$ from resin) as a white powder: HRMS (ESI-TOF) calcd for $\mathrm{C}_{61} \mathrm{H}_{105} \mathrm{~N}_{10} \mathrm{O}_{11}[\mathrm{M}+\mathrm{H}]^{+}$: 1153.7959 ; found: 1153.7958.

$\left[\mathrm{MeAla}^{3}, \operatorname{MeLys}(\mathrm{Me})^{5}, \mathrm{MeAla}^{6}, \mathrm{Phe}\left(4-\mathrm{NO}_{2}\right)^{10}\right]$-Coibamide A (10b). According to the procedure described for the preparation of $\mathbf{2 a}$, peptidyl resin $\mathbf{6}(0.100 \mathrm{mmol})$ was converted into $\mathbf{1 0 b}(17.4 \mathrm{mg}$, $13 \%$ from resin) as a white powder: HRMS (ESI-TOF) calcd for $\mathrm{C}_{61} \mathrm{H}_{104} \mathrm{~N}_{11} \mathrm{O}_{13}[\mathrm{M}+\mathrm{H}]^{+}: 1198.7810$; found: 1198.7809 .

$\left[\mathrm{MeAla}{ }^{3}, \operatorname{MeLys}(\mathrm{Me})^{5}, \mathrm{MeAla}^{6}, \operatorname{Phe}\left(4-\mathrm{CF}_{3}\right)^{10}\right]-\mathrm{Coibamide} \mathrm{A}(10 \mathrm{c})$. According to the procedure described for the preparation of 2a, peptidyl resin $\mathbf{6}(0.100 \mathrm{mmol})$ was converted into $10 \mathbf{c}(32.8 \mathrm{mg}$, 
$25 \%$ from resin) as a white powder: HRMS (ESI-TOF) calcd for $\mathrm{C}_{62} \mathrm{H}_{104} \mathrm{~F}_{3} \mathrm{~N}_{10} \mathrm{O}_{11}[\mathrm{M}+\mathrm{H}]^{+}$: 1221.7833; found: 1221.7832 .

$\left[\mathrm{MeAla}^{3}, \operatorname{MeLys}(\mathrm{Me})^{5}, \mathrm{MeAla}^{6}, \operatorname{Phe}(4-\mathrm{CN})^{10}\right]$-Coibamide A (10d). According to the procedure described for the preparation of $\mathbf{2 a}$, peptidyl resin $\mathbf{6}(0.100 \mathrm{mmol})$ was converted into $10 \mathrm{~d}(23.9 \mathrm{mg}$, $18 \%$ from resin) as a white powder: HRMS (ESI-TOF) calcd for $\mathrm{C}_{62} \mathrm{H}_{104} \mathrm{~N}_{11} \mathrm{O}_{11}[\mathrm{M}+\mathrm{H}]^{+}: 1178.7911$; found: 1178.7911 .

$\left[\mathrm{MeAla}^{3}, \operatorname{MeLys}(\mathrm{Me})^{5}, \mathrm{MeAla}^{6}, \operatorname{Phe}\left(4-\mathrm{N}_{3}\right)^{10}\right]$-Coibamide A (10e). According to the procedure described for the preparation of $\mathbf{2 a}$, peptidyl resin $\mathbf{6}(0.100 \mathrm{mmol})$ was converted into $\mathbf{1 0 e}(5.8 \mathrm{mg}$, 4\% from resin) as a white powder: HRMS (ESI-TOF) calcd for $\mathrm{C}_{61} \mathrm{H}_{104} \mathrm{~N}_{13} \mathrm{O}_{11}[\mathrm{M}+\mathrm{H}]^{+}: 1194.7973$; found: 1194.7974 .

$\left[\mathrm{MeAla}^{3}, \operatorname{MeLys}(\mathrm{Me})^{5}, \mathrm{MeAla}^{6}\right.$, Phe(4-Cl) $\left.{ }^{10}\right]$-Coibamide A (10f). According to the procedure described for the preparation of $\mathbf{2 a}$, peptidyl resin $\mathbf{6}(0.100 \mathrm{mmol})$ was converted into $\mathbf{1 0 f}(25.9 \mathrm{mg}$, $20 \%$ from resin) as a white powder: HRMS (ESI-TOF) calcd for $\mathrm{C}_{61} \mathrm{H}_{104} \mathrm{ClN}_{10} \mathrm{O}_{11}[\mathrm{M}+\mathrm{H}]^{+}$: 1187.7569; found: 1187.7564 .

$\left[\mathrm{MeAla}^{3}, \operatorname{MeLys}(\mathrm{Me})^{5}, \mathrm{MeAla}^{6}\right.$, Phe(4-t-Bu) $\left.{ }^{10}\right]$-Coibamide A (10g). According to the procedure described for the preparation of 2a, peptidyl resin $6(0.100 \mathrm{mmol})$ was converted into $\mathbf{1 0 g}(36.1 \mathrm{mg}$, $27 \%$ from resin) as a white powder: HRMS (ESI-TOF) calcd for $\mathrm{C}_{65} \mathrm{H}_{113} \mathrm{~N}_{10} \mathrm{O}_{11}[\mathrm{M}+\mathrm{H}]^{+}:$1209.8585; found: 1209.8582 .

$\left[\mathrm{MeAla}^{3}, \operatorname{MeLys}(\mathrm{Me})^{5}, \mathrm{MeAla}^{6}, \mathrm{Phe}(4-\mathrm{O} t-\mathrm{Bu})^{10}{ }^{10}\right.$-Coibamide A (10h). According to the procedure described for the preparation of $\mathbf{2 a}$, peptidyl resin $\mathbf{6}(0.100 \mathrm{mmol})$ was converted into $\mathbf{1 0 h}(31.7 \mathrm{mg}$, $24 \%$ from resin) as a white powder: HRMS (ESI-TOF) calcd for $\mathrm{C}_{65} \mathrm{H}_{113} \mathrm{~N}_{10} \mathrm{O}_{12}[\mathrm{M}+\mathrm{H}]^{+}: 1225.8534$; found: 1225.8534 .

$\left[\mathrm{MeAla}{ }^{3}, \operatorname{MeLys}(\mathrm{Me})^{5}, \mathrm{MeAla}^{6}, \operatorname{Phe}\left(4-\mathrm{OCF}_{3}\right)^{10}\right]-\mathrm{Coibamide} \mathrm{A}(10 \mathrm{i})$. According to the procedure described for the preparation of 2a, peptidyl resin $\mathbf{6}(0.100 \mathrm{mmol})$ was converted into $\mathbf{1 0 i}(21.8 \mathrm{mg}$, $16 \%$ from resin) as a white powder: HRMS (ESI-TOF) calcd for $\mathrm{C}_{62} \mathrm{H}_{104} \mathrm{~F}_{3} \mathrm{~N}_{10} \mathrm{O}_{12}[\mathrm{M}+\mathrm{H}]^{+}$: 1237.7782; found: 1237.7784 .

$\left[\mathrm{MeAla}^{3}, \operatorname{MeLys}(\mathrm{Me})^{5}, \mathrm{MeAla}^{6},{ }^{2}-\mathrm{Pal}^{10}{ }^{10}\right.$-Coibamide A (10k). According to the procedure 
described for the preparation of 2a, peptidyl resin $\mathbf{6}(0.100 \mathrm{mmol})$ was converted into $10 \mathrm{k}(7.1 \mathrm{mg}$, $5 \%$ from resin) as a white powder: HRMS (ESI-TOF) calcd for $\mathrm{C}_{60} \mathrm{H}_{105} \mathrm{~N}_{11} \mathrm{O}_{11}[\mathrm{M}+2 \mathrm{H}]^{2+}: 577.8992$; found: 577.8993 .

$\left[\mathrm{MeAla}^{3}, \mathrm{MeLys}(\mathrm{Me})^{5}, \mathrm{MeAla}^{6}, 3-\mathrm{Pal}^{10}{ }^{10}\right.$-Coibamide A (10I). According to the procedure described for the preparation of 2a, peptidyl resin $\mathbf{6}(0.100 \mathrm{mmol})$ was converted into $\mathbf{1 0 1}(31.3 \mathrm{mg}, 23 \%$ from resin) as a white powder: HRMS (ESI-TOF) calcd for $\mathrm{C}_{60} \mathrm{H}_{105} \mathrm{~N}_{11} \mathrm{O}_{11}[\mathrm{M}+2 \mathrm{H}]^{2+}$ : 577.8992; found: 577.8992.

$\left[\mathrm{MeAla}^{3}, \operatorname{MeLys}(\mathrm{Me})^{5}, \mathrm{MeAla}^{6}, 4-\mathrm{Pal}^{10}\right]-$ Coibamide A (10m). According to the procedure described for the preparation of $\mathbf{2 a}$, peptidyl resin $\mathbf{6}(0.100 \mathrm{mmol})$ was converted into $10 \mathrm{~m}(25.0 \mathrm{mg}$, $18 \%$ from resin) as a white powder: HRMS (ESI-TOF) calcd for $\mathrm{C}_{60} \mathrm{H}_{105} \mathrm{~N}_{11} \mathrm{O}_{11}[\mathrm{M}+2 \mathrm{H}]^{2+}: 577.8992$; found: 577.8991 .

$\left[\mathrm{MeAla}^{3}, \operatorname{MeLys}(\mathrm{Me})^{5}, \mathrm{MeAla}^{6}, \mathrm{MePhe}^{10}\right]$-Coibamide A (10n). According to the procedure described for the preparation of 2a, peptidyl resin $6(0.100 \mathrm{mmol})$ was converted into $10 \mathrm{n}(2.0 \mathrm{mg}$, $2 \%$ from resin) as a white powder: HRMS (ESI-TOF) calcd for $\mathrm{C}_{62} \mathrm{H}_{107} \mathrm{~N}_{10} \mathrm{O}_{11}[\mathrm{M}+\mathrm{H}]^{+}: 1167.8115$; found: 1167.8116 .

$\left[\mathrm{MeAla}^{3}, \operatorname{MeLys}(\mathrm{Me})^{5}, \mathrm{MeAla}^{6}\right.$, Tic $\left.^{10}\right]$-Coibamide A (100). According to the procedure described for the preparation of $\mathbf{2 a}$, peptidyl resin $\mathbf{6}(0.100 \mathrm{mmol})$ was converted into $\mathbf{1 0 0}(8.9 \mathrm{mg}, 7 \%$ from resin) as a white powder: HRMS (ESI-TOF) calcd for $\mathrm{C}_{62} \mathrm{H}_{105} \mathrm{~N}_{10} \mathrm{O}_{11}[\mathrm{M}+\mathrm{H}]^{+}:$1165.7959; found: 1165.7959.

$\left[\mathrm{MeAla}^{3}, \operatorname{MeLys}(\mathrm{Me})^{5}, \mathrm{MeAla}^{6}\right.$, 1-Nal $\left.{ }^{10}\right]-C o i b a m i d e ~ A ~(10 p)$. According to the procedure described for the preparation of $\mathbf{2 a}$, peptidyl resin $\mathbf{6}(0.100 \mathrm{mmol})$ was converted into $10 \mathbf{p}(5.8 \mathrm{mg}$, $4 \%$ from resin) as a white powder: HRMS (ESI-TOF) calcd for $\mathrm{C}_{65} \mathrm{H}_{107} \mathrm{~N}_{10} \mathrm{O}_{11}[\mathrm{M}+\mathrm{H}]^{+}: 1203.8115$; found: 1203.8114 .

$\left[\mathrm{MeAla}^{3}, \operatorname{MeLys}(\mathrm{Me})^{5}, \mathrm{MeAla}^{6}, 2-\mathrm{Nal}^{10}\right]$-Coibamide A (10q). According to the procedure described for the preparation of $\mathbf{2 a}$, peptidyl resin $\mathbf{6}(0.100 \mathrm{mmol})$ was converted into $\mathbf{1 0 q}(5.5 \mathrm{mg}$, $4 \%$ from resin) as a white powder: HRMS (ESI-TOF) calcd for $\mathrm{C}_{65} \mathrm{H}_{107} \mathrm{~N}_{10} \mathrm{O}_{11}[\mathrm{M}+\mathrm{H}]^{+}: 1203.8115$; found: 1203.8112 .

$\left[\mathbf{B p h}^{10}\right]$-Coibamide A (11). The linear peptides were constructed by solid-phase peptide synthesis on 
peptidyl resin $\mathbf{S 3}(0.712 \mathrm{mmol} / \mathrm{g}, 422 \mathrm{mg}, 0.300 \mathrm{mmol})$. Fmoc- or Alloc- protected amino acids (0.900 mmol) were coupled at $40{ }^{\circ} \mathrm{C}$ by using DIC $(139 \mu \mathrm{L}, 0.900 \mathrm{mmol})$ and HOAt (122 $\left.\mathrm{mg}, 0.900 \mathrm{mmol}\right)$ in DMF. Fmoc-D-MeAla-OH (488 mg, $1.50 \mathrm{mmol}$ ) was coupled onto the hydroxy group of MeThr ${ }^{5}$ at room temperature using DIC $(232 \mu \mathrm{L}, 1.50 \mathrm{mmol})$ and DMAP (55 mg, $0.45 \mathrm{mmol})$ in dry DCE. After cleavage from the resin $\mathbf{S 7}$ as described above, HATU (570 mg, $1.50 \mathrm{mmol}$ ) and DIEA (1.05 $\mathrm{mL}, 6.00 \mathrm{mmol})$ were added to a solution of crude linear peptide in dry $\mathrm{CH}_{2} \mathrm{Cl}_{2}(300 \mathrm{~mL})$. The reaction mixture was stirred for $12 \mathrm{~h}$. After the mixture was concentrated, the residue was purified by RPHPLC to give 11 (26.5 mg, 6.1\% from resin) as a white powder: ${ }^{1} \mathrm{H}$ NMR (500 MHz, $\mathrm{CDCl}_{3}$, mixture of rotamers) $\delta: 0.61-1.17(\mathrm{~m}, 33 \mathrm{H}), 1.17-1.48(\mathrm{~m}, 11 \mathrm{H}), 1.48-1.61(\mathrm{~m}, 2 \mathrm{H}), 1.61-1.73(\mathrm{~m}, 1 \mathrm{H}), 2.01$ $2.15(\mathrm{~m}, 1 \mathrm{H}), 2.15-2.33(\mathrm{~m}, 2 \mathrm{H}), 2.35-2.87(\mathrm{~m}, 9 \mathrm{H}), 2.87-3.06(\mathrm{~m}, 15 \mathrm{H}), 3.06-3.43(\mathrm{~m}, 12 \mathrm{H}), 3.44-$ $3.57(\mathrm{~m}, 1 \mathrm{H}), 3.57-3.73(\mathrm{~m}, 2 \mathrm{H}), 3.73-3.82(\mathrm{~m}, 1 \mathrm{H}), 3.82-3.95(\mathrm{~m}, 2 \mathrm{H}), 4.71-4.87(\mathrm{~m}, 1 \mathrm{H}), 5.06(\mathrm{~d}$, $J=4.5 \mathrm{~Hz}, 1 \mathrm{H}), 5.13-5.23$ (m, 1H), 5.23-5.30 (m, 1H), 5.30-5.46 (m, 1H), 5.46-5.59 (m, 1H), 5.68$5.84(\mathrm{~m}, 1 \mathrm{H})$, 5.84-6.05 (m, 1H), 6.20-6.44 (m, 1H), 6.54-6.70 (m, 1H), 6.82-7.11 (m, 1H), $7.25(\mathrm{~d}$, $J=7.0 \mathrm{~Hz}, 1 \mathrm{H}), 7.29-7.39(\mathrm{~m}, 2 \mathrm{H}), 7.39-7.60(\mathrm{~m}, 6 \mathrm{H}) ;{ }^{13} \mathrm{C} \mathrm{NMR}\left(125 \mathrm{MHz}, \mathrm{CDCl}_{3}\right.$, mixture of rotamers) $\delta: 11.6,12.9,13.0,15.8,16.6,17.5,18.6,18.7,19.0,19.1,21.0,21.11,21.14,21.5,22.1$, 23.1, 23.2, 23.3, 23.4, 24.3, 25.3, 28.2, 28.9, 29.1, 29.7, 29.9, 30.1, 30.2 , 30.4, 31.0, 32.0, 36.6, 37.6, 38.8, 39.7, 47.0, 50.0, 51.3, 51.5, 51.7, 52.9, 53.1, 53.3, 58.8, 63.6, 64.7, 68.2, 68.6, 68.9, 69.0, 71.0, 77.6, 126.7, 126.88, 126.93, 127.1, 127.2, 127.4, 128.8, 129.7, 130.0, 130.1, 135.3, 140.0, 140.5, 167.2, 168.0, 168.5, 168.6, 169.15, 169.22, 169.6, 170.0, 170.3, 170.6, 170.7, 171.2, 171.6, 172.0; HRMS (ESI-TOF) calcd for $\mathrm{C}_{70} \mathrm{H}_{114} \mathrm{~N}_{10} \mathrm{O}_{15}[\mathrm{M}+2 \mathrm{H}]^{2+}: 667.4227$; found: 667.4227 .

$\left[\mathrm{MeAla}^{3}, \mathrm{MeAla}^{6}, \mathbf{B p h}^{10}\right]$-Coibamide A (12). According to the procedure described for the preparation of 11, peptidyl resin $\mathbf{S 3}(0.712 \mathrm{mmol} / \mathrm{g}, 422 \mathrm{mg}, 0.300 \mathrm{mmol})$ was converted into $12(30.3$ $\mathrm{mg}, 7.3 \%$ from resin) as a white powder: ${ }^{1} \mathrm{H} \mathrm{NMR}\left(500 \mathrm{MHz}, \mathrm{CDCl}_{3}\right.$, mixture of rotamers) $\delta$ : 0.620.84 (d, $J=6.0 \mathrm{~Hz}, 3 \mathrm{H}), 0.86-0.99$ (m, 15H), 0.99-1.06 (m, 8H), 1.08 (d, $J=7.0 \mathrm{~Hz}, 3 \mathrm{H}), 1.11(\mathrm{~d}, J$ $=7.0 \mathrm{~Hz}, 3 \mathrm{H}), 1.13-1.24(\mathrm{~m}, 8 \mathrm{H}), 1.24-1.34(\mathrm{~m}, 9 \mathrm{H}), 1.34-1.45(\mathrm{~m}, 2 \mathrm{H}), 1.45-1.59$ (m, 2H), $1.64-$ $1.74(\mathrm{~m}, 1 \mathrm{H}), 2.01-2.10(\mathrm{~m}, 1 \mathrm{H}), 2.15-2.30(\mathrm{~m}, 2 \mathrm{H}), 2.33-2.72(\mathrm{~m}, 4 \mathrm{H}), 2.76(\mathrm{~s}, 3 \mathrm{H}), 2.87(\mathrm{~s}, 3 \mathrm{H})$, 2.89-3.23 (m, 20H), 3.63-3.83 (m, 2H), $3.87(\mathrm{~d}, J=9.0 \mathrm{~Hz}, 1 \mathrm{H}), 4.74-4.90(\mathrm{~m}, 1 \mathrm{H}), 5.01(\mathrm{~d}, J=4.5$ $\mathrm{Hz}, 1 \mathrm{H}), 5.06-5.71(\mathrm{~m}, 6 \mathrm{H}), 6.32-6.61(\mathrm{~m}, 1 \mathrm{H}), 7.23-7.31(\mathrm{~m}, 2 \mathrm{H}), 7.35(\mathrm{t}, J=7.5 \mathrm{~Hz}, 1 \mathrm{H}), 7.44(\mathrm{t}, J$ $=7.5 \mathrm{~Hz}, 2 \mathrm{H}), 7.46-7.60(\mathrm{~m}, 4 \mathrm{H}) ;{ }^{13} \mathrm{C} \mathrm{NMR}\left(125 \mathrm{MHz}, \mathrm{CDCl}_{3}\right.$, mixture of rotamers) $\delta: 11.5,11.7$, $12.7,12.8,14.0,14.4,14.6,15.6,15.8,16.0,16.7,18.5,18.9,19.0,21.0,21.2,21.9,23.0,23.2,23.4$, 24.1, 25.1, 25.2, 28.0, 28.9, 29.0, 29.5, 29.6, 29.9, 30.1, 30.7, 32.1, 36.6, 37.5, 38.0, 38.7, 39.5, 46.4, 46.7, 50.0, 50.2, 50.3, 50.6, 51.1, 51.2, 51.4, 51.6, 57.3, 64.6, 68.8, 70.8, 70.9, 77.1, 126.6, 126.7, 126.8, 127.0, 127.1, 127.3, 128.7, 129.6, 130.0, 134.9, 137.1, 139.1, 140.0, 140.3, 140.6, 167.4, 167.6, 
167.7, 168.5, 169.2, 169.9, 170.4, 170.6, 171.4, 171.5, 171.8, 171.9, 172.8, 173.7; HRMS (ESI-TOF) calcd for $\mathrm{C}_{68} \mathrm{H}_{108} \mathrm{~N}_{10} \mathrm{NaO}_{13}[\mathrm{M}+\mathrm{Na}]^{+}:$1295.7990; found: 1295.7976.

\section{Growth Inhibition Assay ${ }^{\mathrm{S} 3}$}

A549 cells were cultured in Dulbecco's modified Eagle's medium (DMEM; Sigma) supplemented with $10 \%(\mathrm{v} / \mathrm{v})$ fetal bovine serum at $37{ }^{\circ} \mathrm{C}$ in a $5 \% \mathrm{CO}_{2}$-incubator. Growth inhibition assays using A549 cells were performed in 96-well plates (BD Falcon). A549 cells were seeded at 1000 cells/well in $90 \mu \mathrm{L}$ of culture media, respectively, and were cultured for $24 \mathrm{~h}$. Chemical compounds in DMSO were diluted 50 -fold with the culture medium in advance. $30 \mu \mathrm{L}$ of the chemical diluents were added. The final volume of DMSO in the medium was equal to $0.5 \%(\mathrm{v} / \mathrm{v})$. The cells under chemical treatment were incubated for a further $72 \mathrm{~h}$. The wells in the plates were washed twice with the cultured medium without phenol-red. After 1-hour incubation with $100 \mu \mathrm{L}$ of the medium, the cell culture in each well was supplemented with $20 \mu \mathrm{L}$ of the MTS reagent (Promega), followed by incubation for additional $40 \mathrm{~min}$. Absorbance at $490 \mathrm{~nm}$ of each well was measured using a Wallac 1420 ARVO SX multilabel counter (Perkin Elmer). Three experiments were performed per condition and the averages of inhibition rates in each condition were evaluated to determine IC $_{50}$ values using the GraphPad Prism software. 

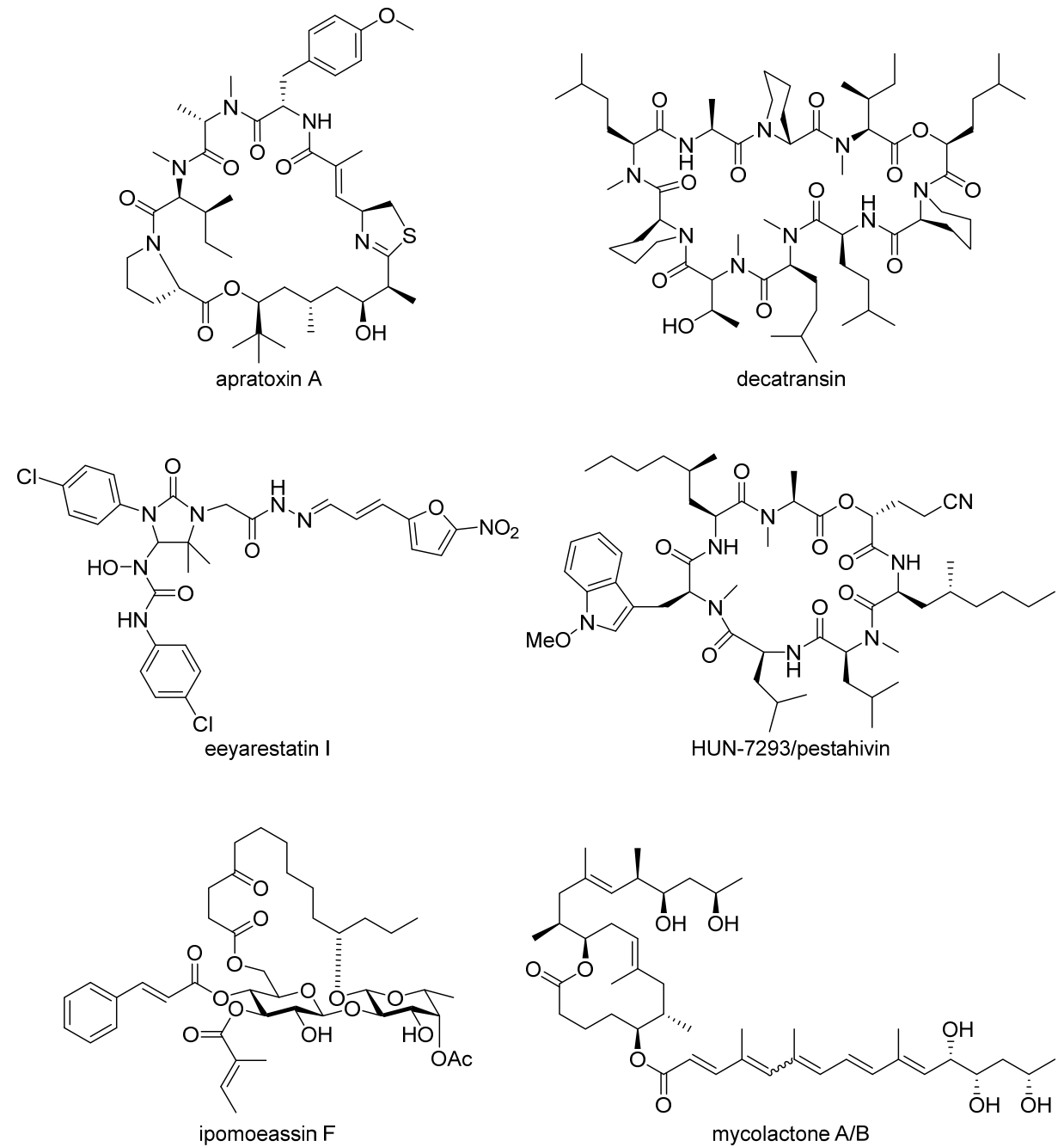

Figure S1. Structures of natural product Sec61 inhibitors. 


\section{Synthesis of $\left[\mathrm{Bph}^{10}\right]-$ Coibamide $\mathrm{A}$}

The peptide was assembled on H-MeIle-(2-Cl)Trt resin by Fmoc-SPPS. Coupling of Ser(Me) ${ }^{6}$ followed by on-resin N-methylation ${ }^{\mathrm{S} 4}$ provided peptidyl resin S5. MeThr ${ }^{5}$, MeLeu ${ }^{4}$, and MeSer(Me) ${ }^{3}$ were efficiently coupled onto $N$-methylamino acids using DIC/HOAt. Coupling of the N-terminal $\mathrm{Me}_{2} \mathrm{Val}^{1}$-D-Hva ${ }^{2}$ moiety using HATU/DIEA gave the peptidyl resin S6. Subsequently, Fmoc-DMeAla-OH was coupled onto the MeThr ${ }^{5}$ hydroxy group using DIC/DMAP. To avoid the diketopiperazine formation under basic condition for deprotection of the Fmoc group, Alloc protection was employed for $\mathrm{Bph}^{10}$, which can be removed under neutral condition. After coupling of Alloc-Bph-OH using DIC/HOAt followed by deprotection of the Alloc group, MeLeu ${ }^{9}$ and Ala ${ }^{8}$ were coupled using DIC/HOBt and DIC/HOAt, respectively. Cleavage of the open-chain peptide $\mathbf{S} 7$ from the resin and macrocyclization with HATU/DIEA in $\mathrm{CH}_{2} \mathrm{Cl}_{2}{ }^{\mathrm{S} 5}$ gave the desired product 11 .

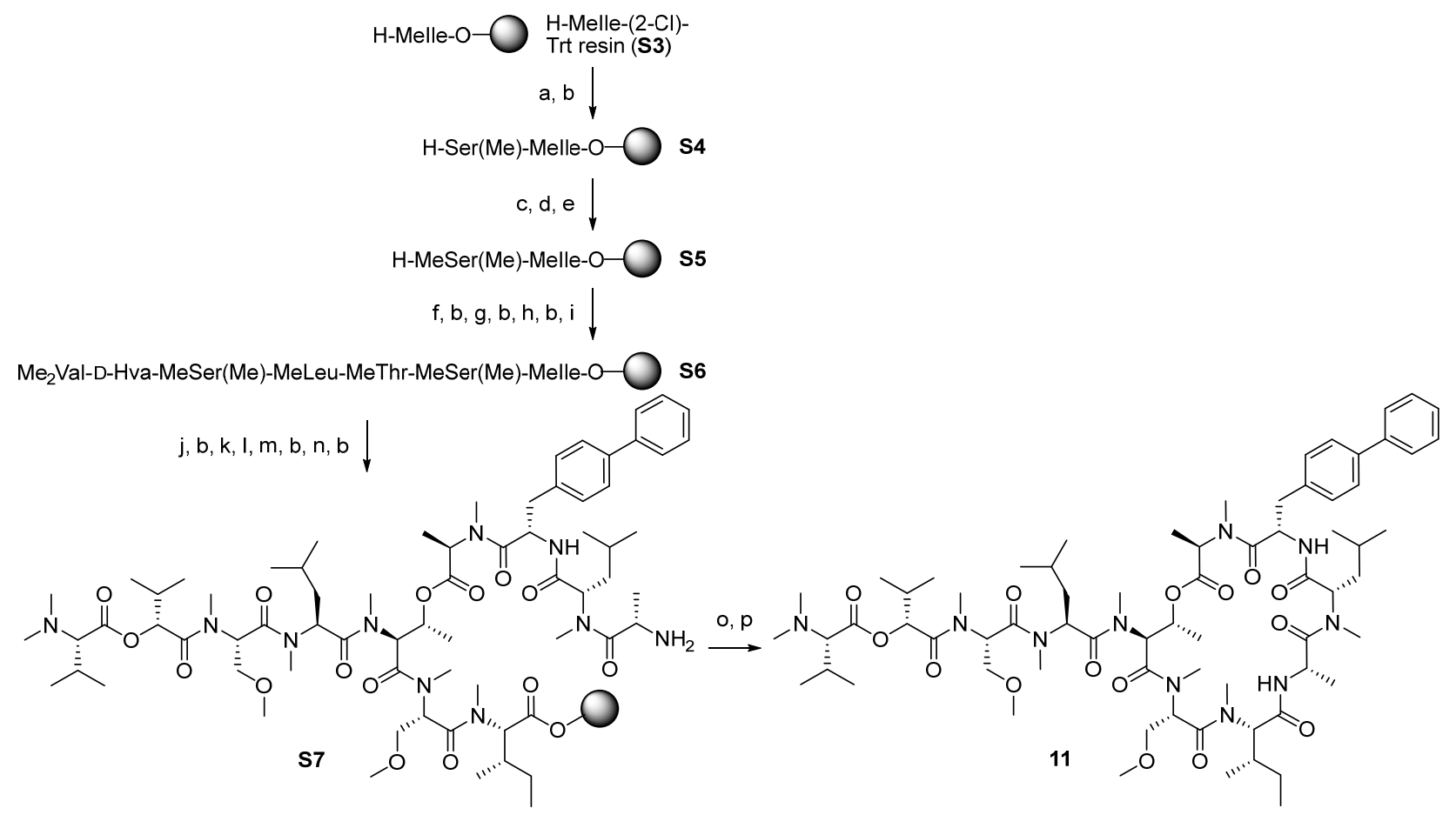

Scheme S1. Synthesis of [Bph $\left.{ }^{10}\right]$-coibamide A (11). Reagents and conditions: (a) Fmoc-Ser(Me)-OH, DIC, HOAt, DMF, $40{ }^{\circ} \mathrm{C}$; (b) $20 \%$ piperidine/DMF, rt; (c) NsCl, 2,4,6-collidine, NMP, rt; (d) $\mathrm{Ph}_{3} \mathrm{P}$, DEAD, MeOH, THF, rt; (e) 2-mercaptoethanol, DBU, NMP, rt; (f) Fmoc-MeThr-OH, DIC, HOAt, DMF, $40^{\circ} \mathrm{C}$; (g) Fmoc-MeLeu-OH, DIC, HOAt, DMF, $40^{\circ} \mathrm{C}$ (h) Fmoc-MeSer(Me)-OH, DIC, HOAt, DMF, $40{ }^{\circ} \mathrm{C}$; (i) Me 2 Val-D-Hva-OH, HATU, DIEA, DMF, $40{ }^{\circ} \mathrm{C}$; (j) Fmoc-D-MeAla-OH, DIC, DMAP, 1,2-DCE, rt; (k) Alloc-Bph-OH, DIC, HOAt, DMF, $40{ }^{\circ} \mathrm{C}$; (l) $\mathrm{Pd}\left(\mathrm{PPh}_{3}\right) 4, \mathrm{PhSiH}_{3}, \mathrm{CH}_{2} \mathrm{Cl}_{2}$, rt; (m) Fmoc-MeLeu-OH, DIC, HOBt $\cdot \mathrm{H}_{2} \mathrm{O}$, DMF, $40{ }^{\circ} \mathrm{C}$; (n) Fmoc-Ala-OH$\cdot \mathrm{H}_{2} \mathrm{O}$, DIC, HOAt, DMF, $40{ }^{\circ} \mathrm{C}$; (o) $30 \% \mathrm{HFIP} / \mathrm{CH}_{2} \mathrm{Cl}_{2}$, rt; (p) HATU, DIEA, $\mathrm{CH}_{2} \mathrm{Cl}_{2}$. 


\section{References and Notes}

S1 Freidinger, R. M.; Hinkle, J. S.; Perlow, D. S.; Arison, B. H. Synthesis of 9fluorenylmethyloxycarbonyl-protected $N$-alkyl amino acids by reduction of oxazolidinones. $J$. Org. Chem. 1983, 48, 77-81.

S2 Nabika, R.; Suyama, T. L.; Hau, A. M.; Misu, R.; Ohno, H.; Ishmael, J. E.; McPhail, K. L.; Oishi, S.; Fujii, N. Synthesis and biological evaluation of the [D-MeAla $\left.{ }^{11}\right]$-epimer of coibamide A. Bioorg. Med. Chem. Lett. 2015, 25, 302-306.

S3 Hou, Z.; Nakanishi, I.; Kinoshita, T.; Takei, Y.; Yasue, M.; Misu, R.; Suzuki, Y.; Nakamura, S.; Kure, T.; Ohno, H.; Murata, K.; Kitaura, K.; Hirasawa, A.; Tsujimoto, G.; Oishi, S.; Fujii, N. Structure-based design of novel potent protein kinase CK2 (CK2) inhibitors with phenyl-azole scaffolds. J. Med. Chem. 2012, 55, 2899-2903.

S4 Biron, E.; Chatterjee, J.; Kessler, H. Optimized selective N-methylation of peptides on solid support. J. Pept. Sci. 2006, 12, 213-219.

S5 Pan, Z.; Wu, C.; Wang, W.; Cheng, Z.; Yao, G.; Liu, K.; Li, H.; Fang, L.; Su, W. Total synthesis and stereochemical assignment of gymnopeptides A and B. Org. Lett. 2017, 19, 4420-4423. 


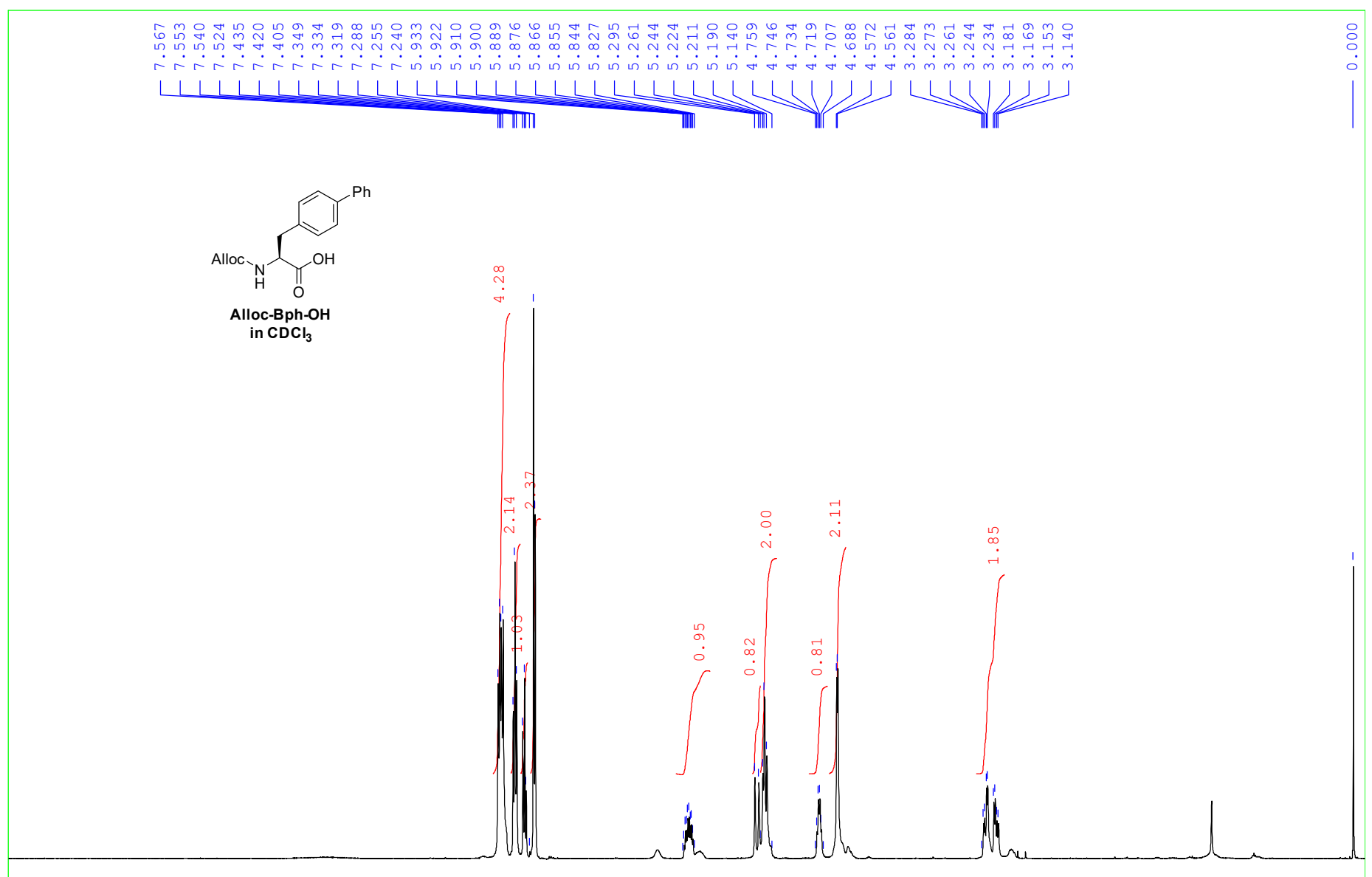

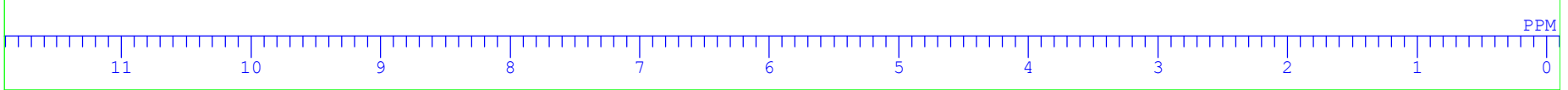

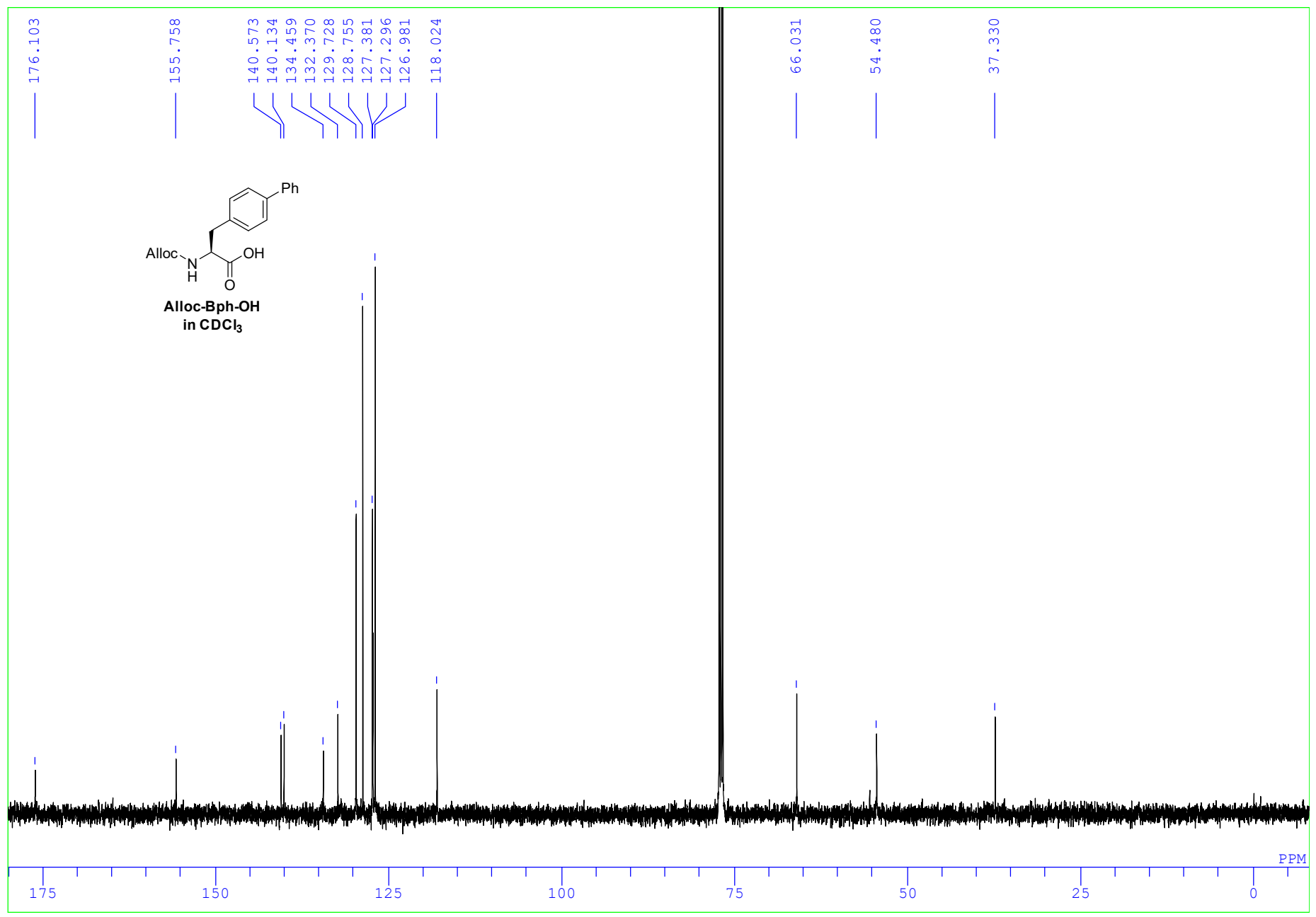




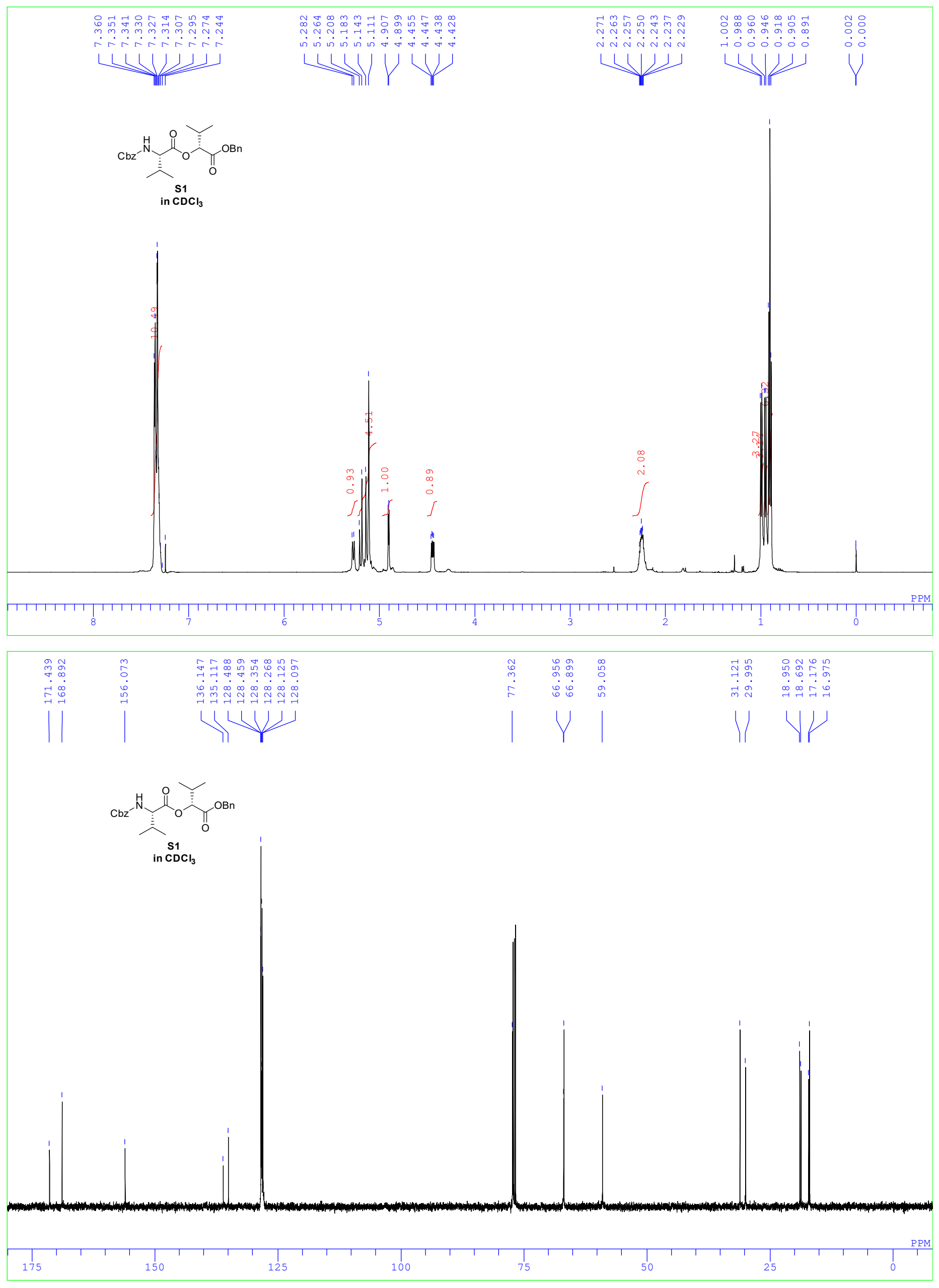




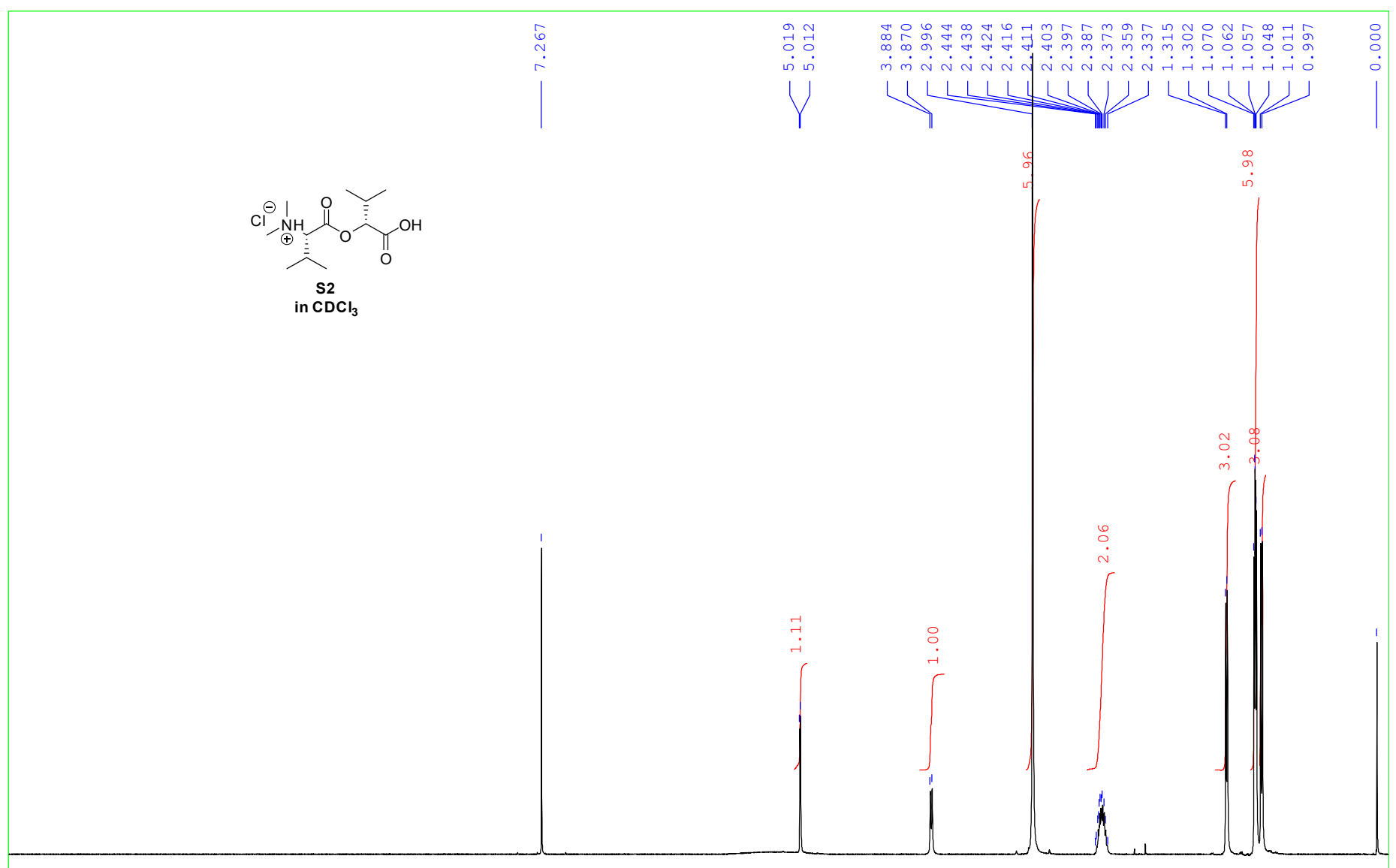

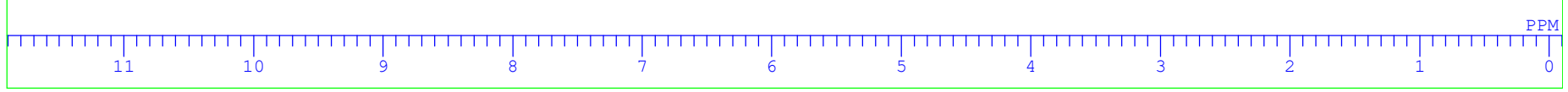

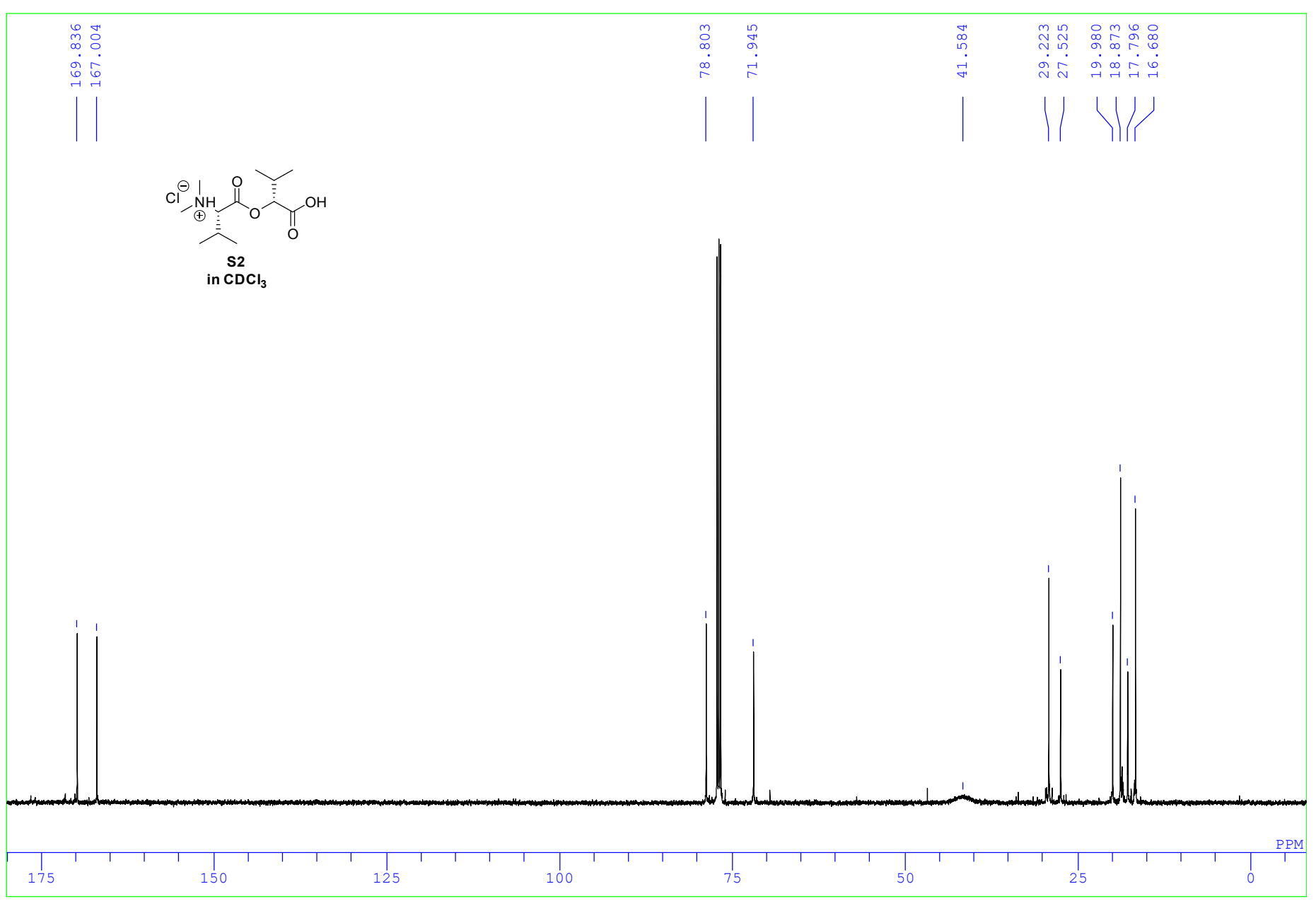



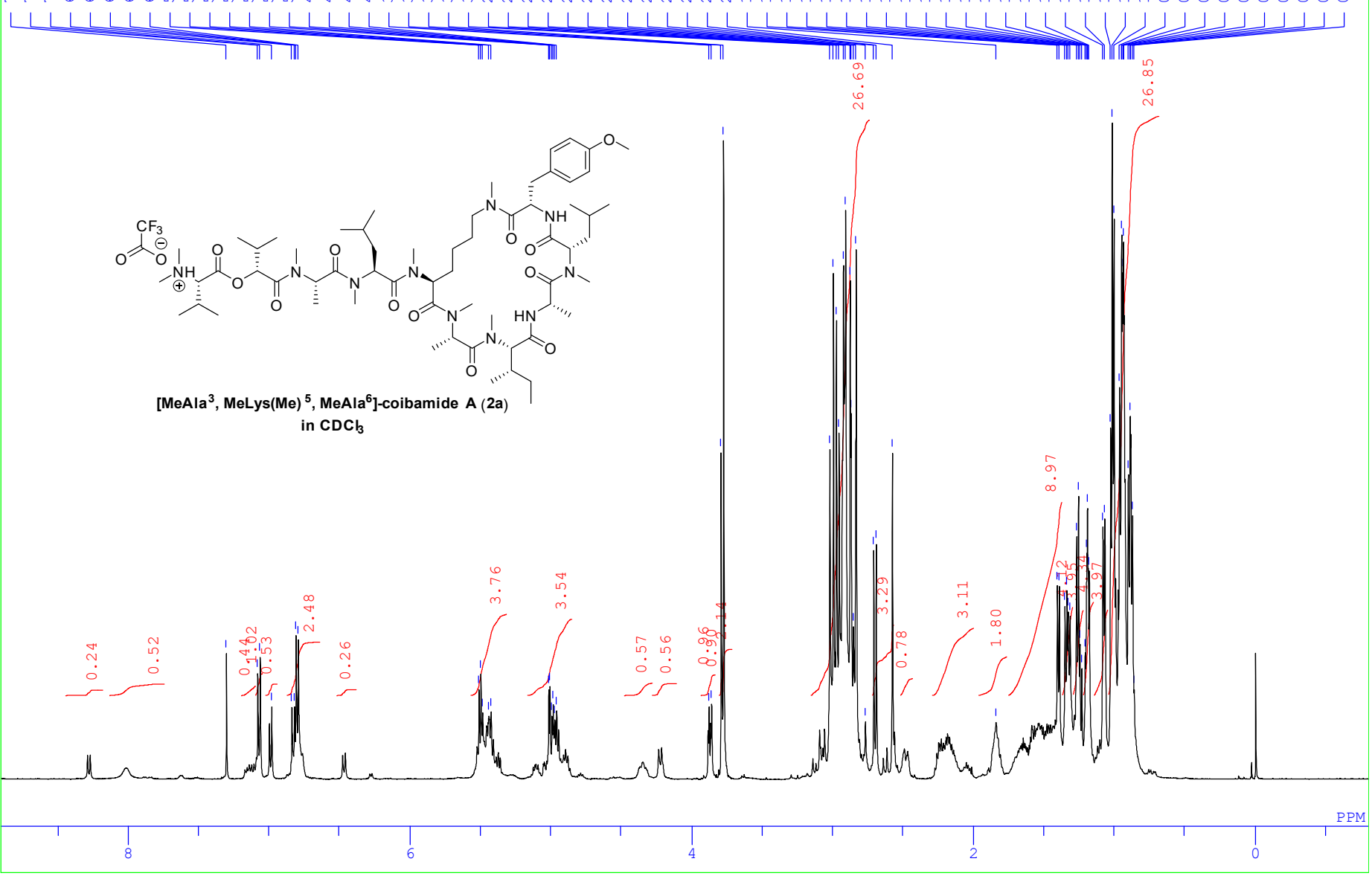

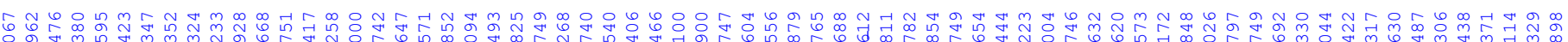

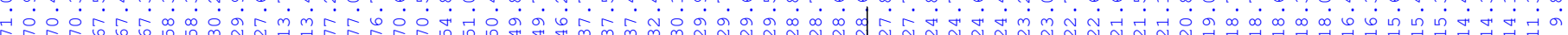

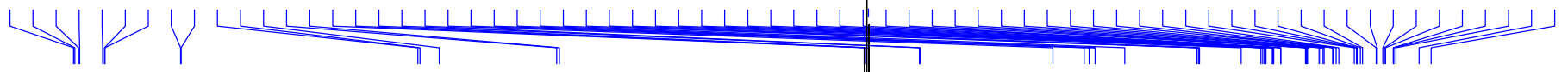

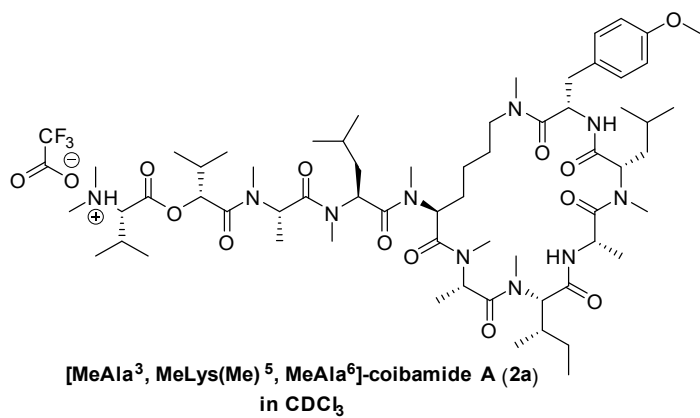




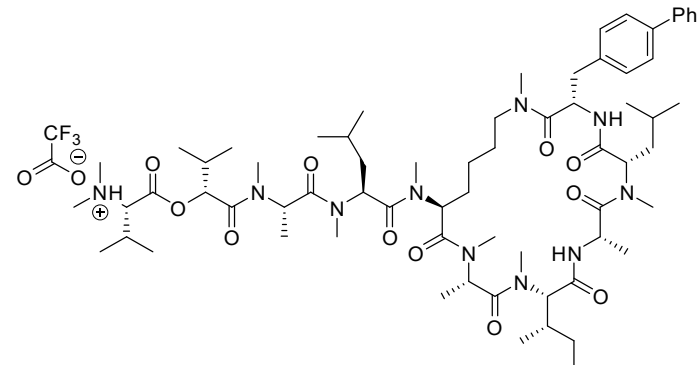

$\left[\mathrm{MeAla}{ }^{3}, \operatorname{MeLys}(\mathrm{Me})^{5}, \mathrm{MeAla}^{6}, \mathrm{Bph}^{10}\right]$-coibamide A $(10 \mathrm{j})$ in $\mathrm{CDCl}_{3}$

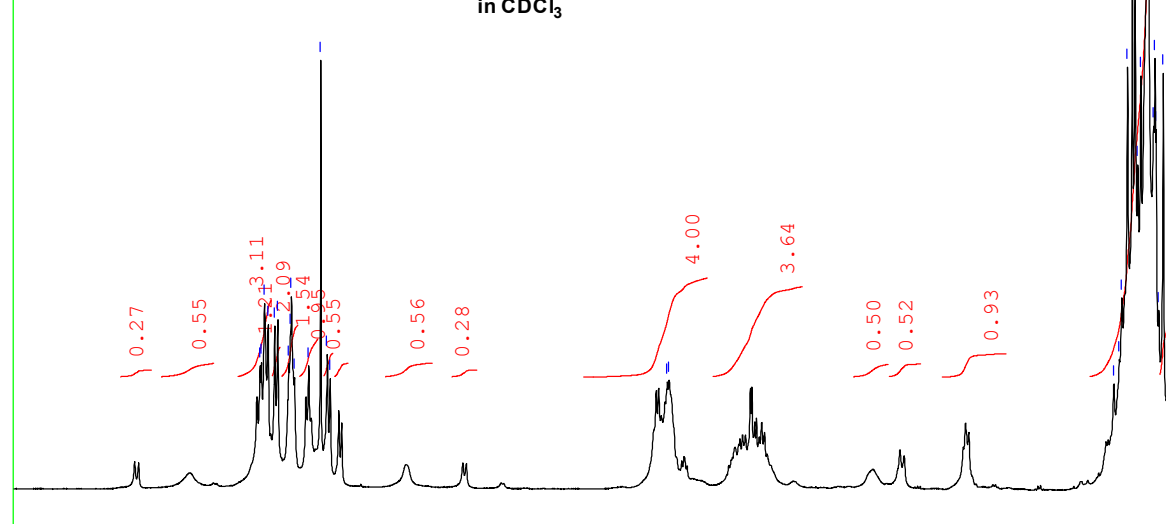

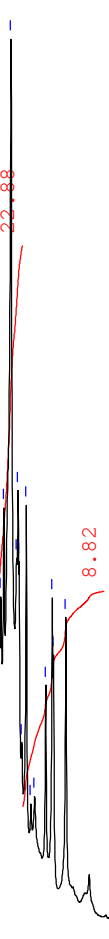
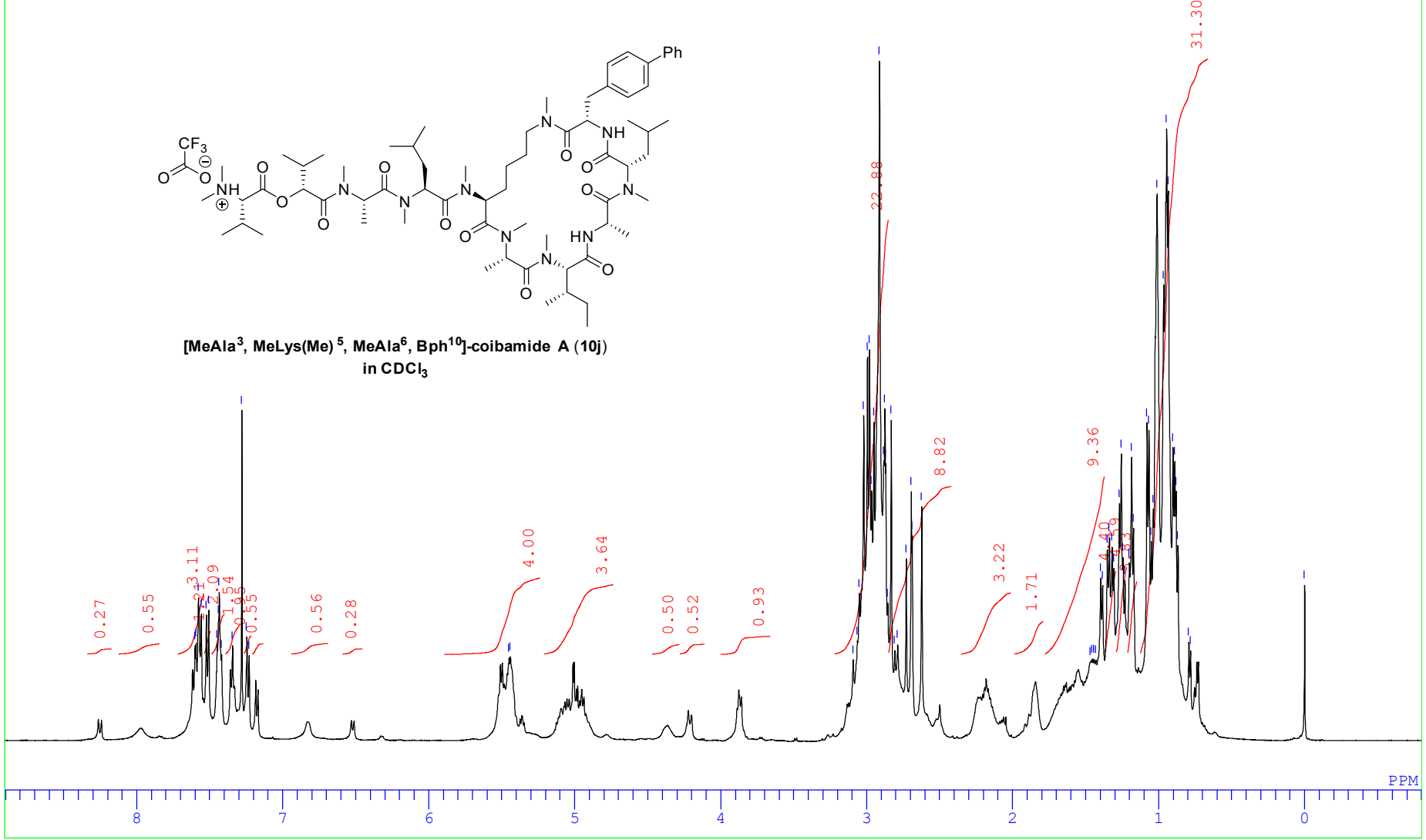

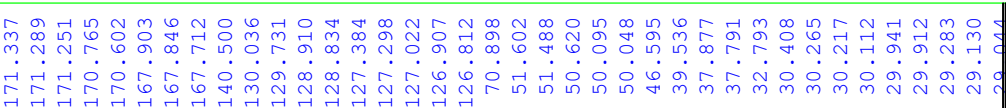

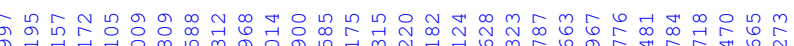

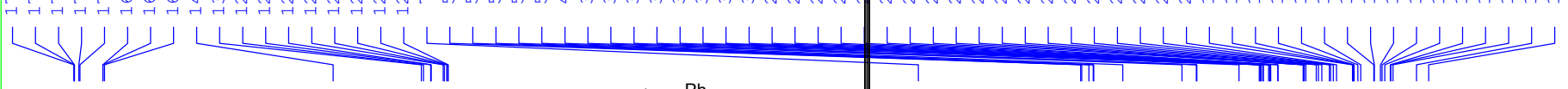
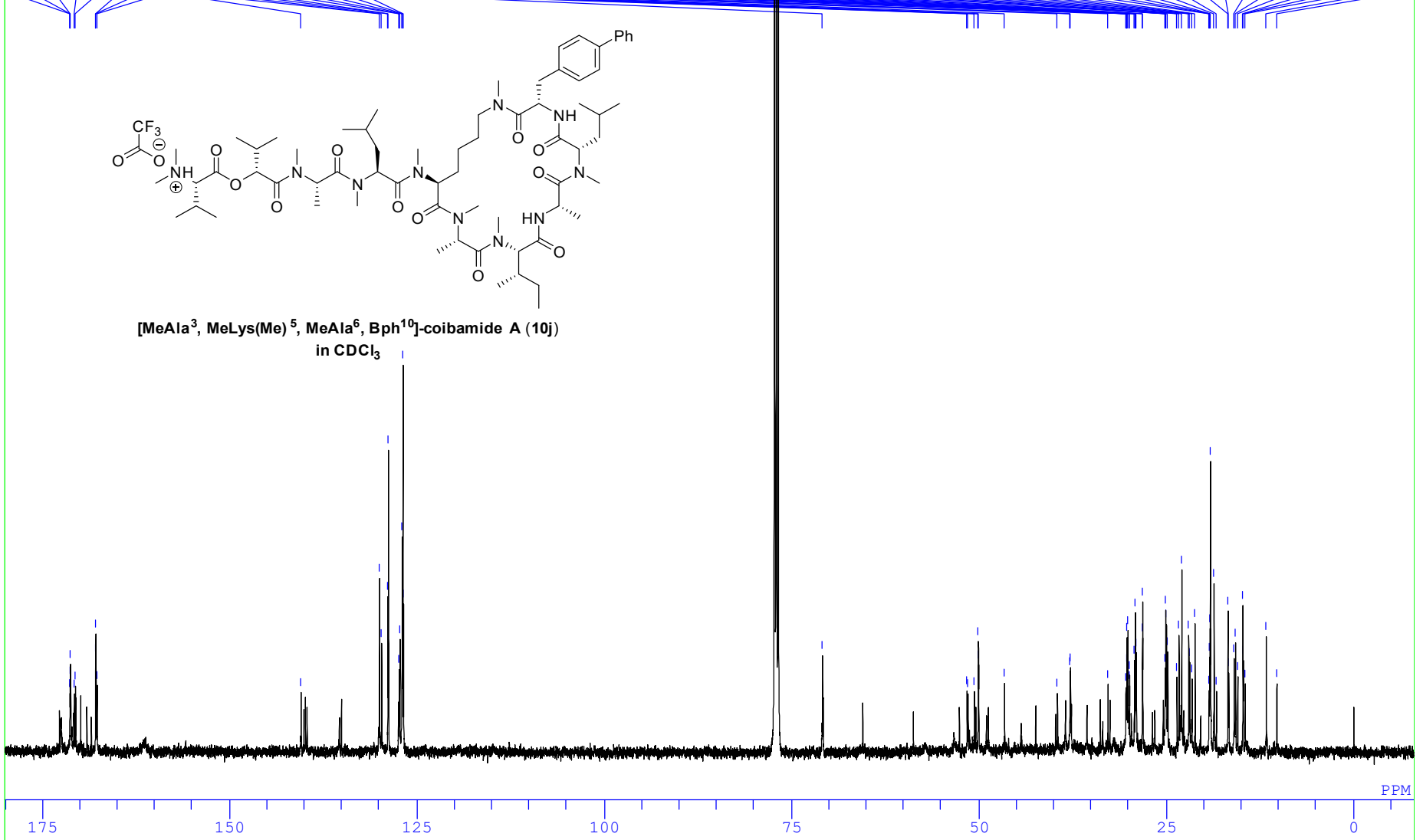

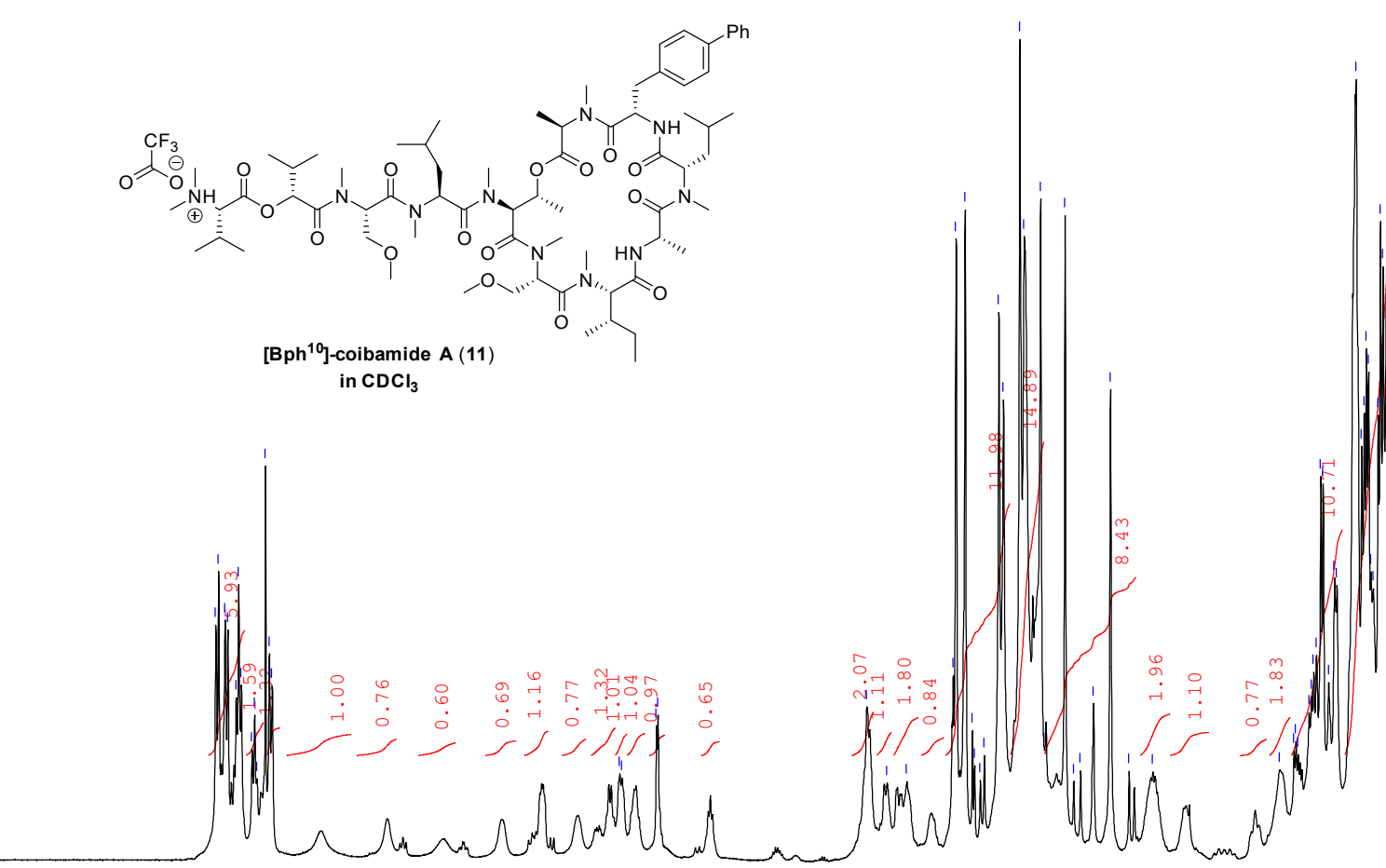

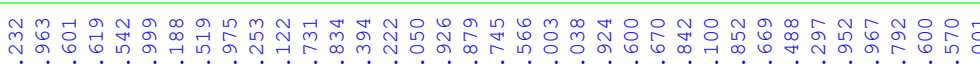

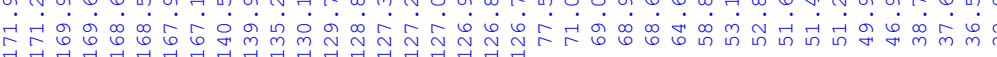

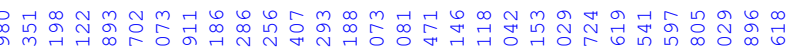
(1)

HII

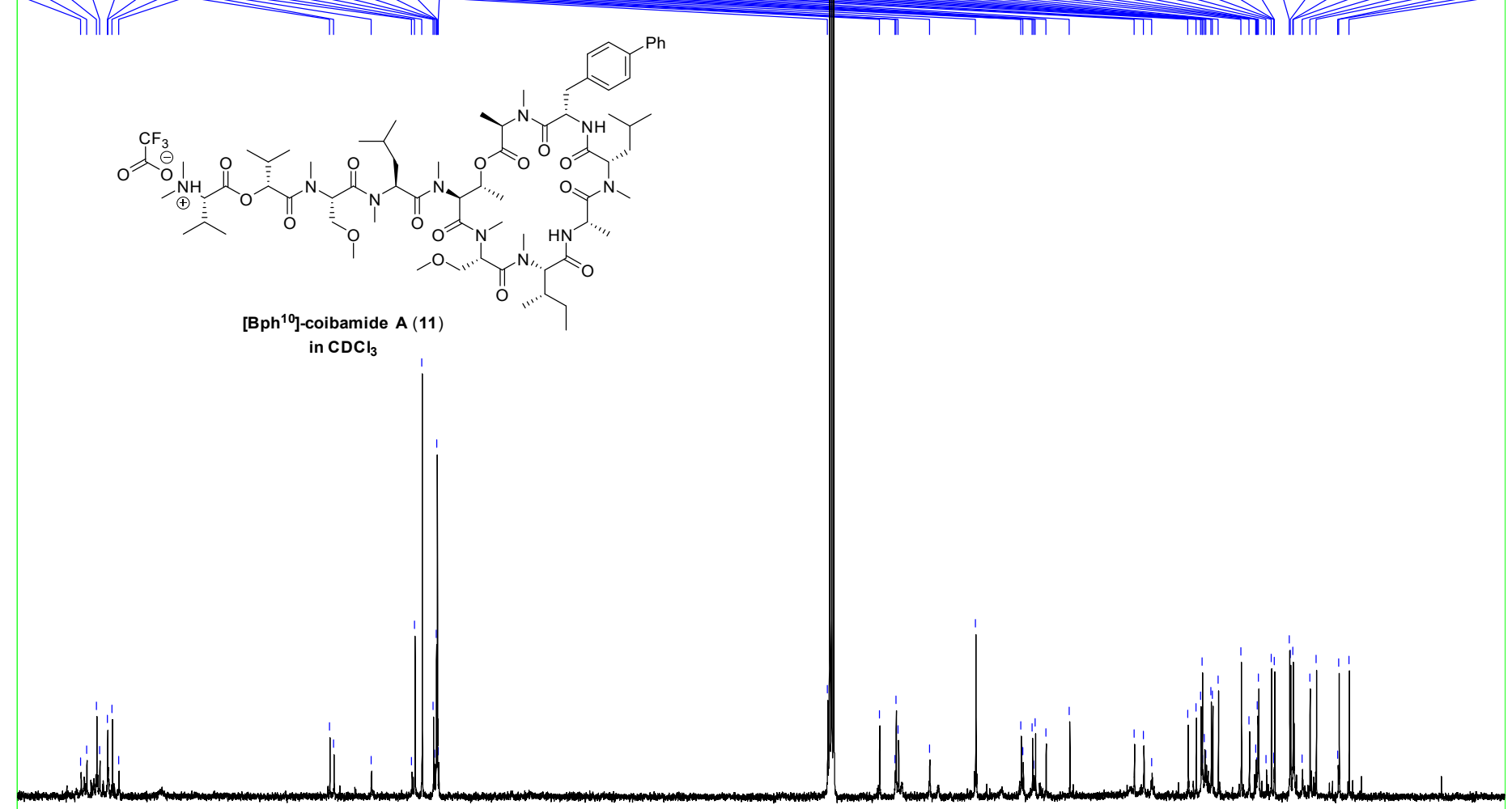

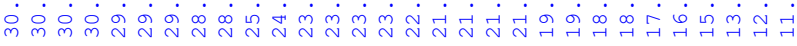




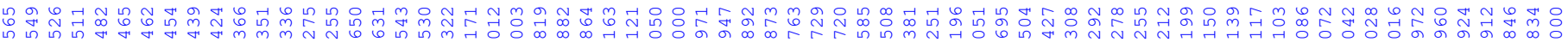
-

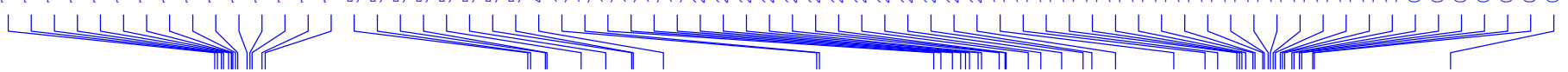

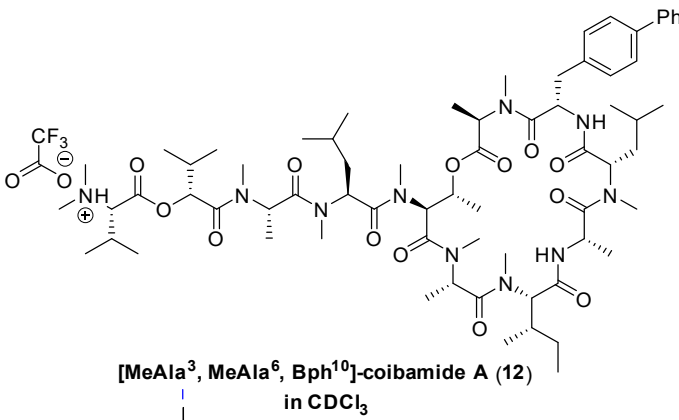

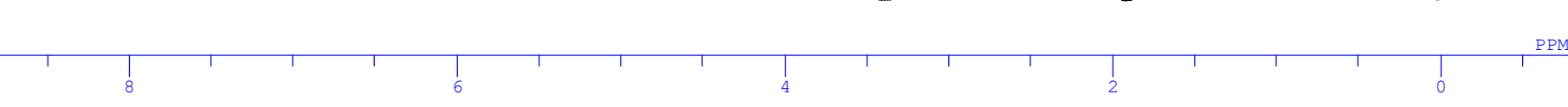

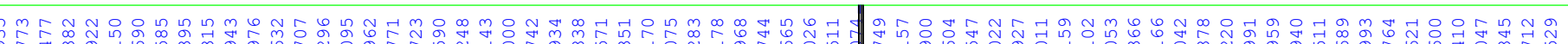

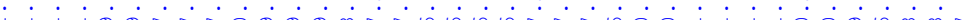

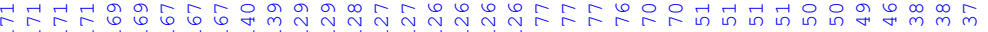
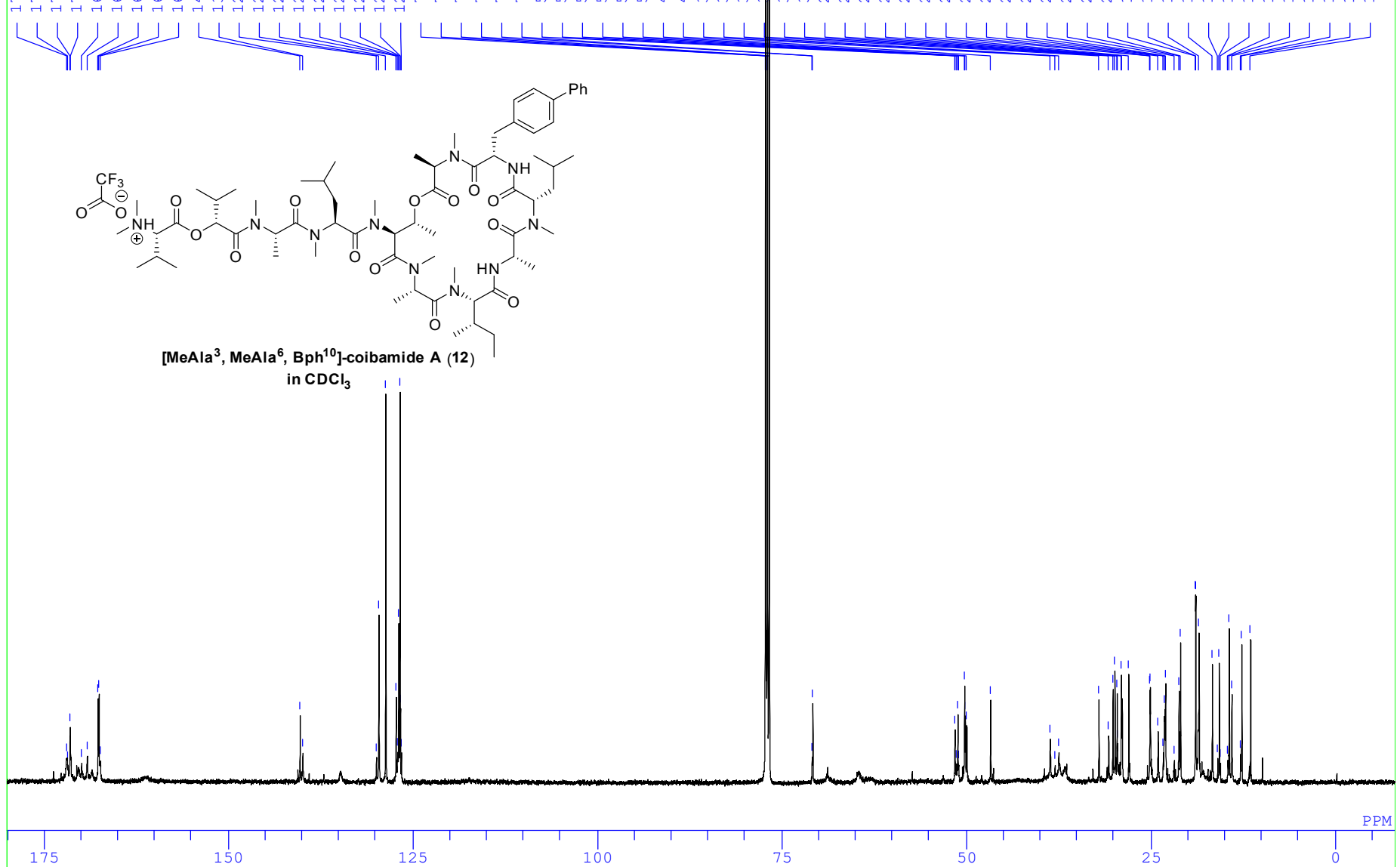

100 